\title{
Growth reaction norms of domesticated, wild and hybrid Atlantic salmon families in response to differing social and physical environments
}

\author{
Monica Favnebøe Solberg ${ }^{1,2^{*}}$, Zhiwei Zhang ${ }^{3}$, Frank Nilsen² and Kevin Alan Glover ${ }^{1}$
}

\begin{abstract}
Background: Directional selection for growth has resulted in the 9-10th generation of domesticated Atlantic salmon Salmo salar L. outgrowing wild salmon by a ratio of approximately 3:1 when reared under standard hatchery conditions. In the wild however, growth of domesticated and wild salmon is more similar, and seems to differ at the most by a ratio of 1.25:1. Comparative studies of quantitative traits in farmed and wild salmon are often performed by the use of common-garden experiments where salmon of all origins are reared together to avoid origin-specific environmental differences. As social interaction may influence growth, the large observed difference in growth between wild and domesticated salmon in the hatchery may not be entirely genetically based, but inflated by inter-strain competition. This study had two primary aims: (i) investigate the effect of social interaction and inter-strain competition in common-garden experiments, by comparing the relative growth of farmed, hybrid and wild salmon when reared together and separately; (ii) investigate the competitive balance between wild and farmed salmon by comparing their norm of reaction for survival and growth along an environmental gradient ranging from standard hatchery conditions to a semi-natural environment with restricted feed.

Results: The main results of this study, which are based upon the analysis of more than 6000 juvenile salmon, can be summarised as; (i) there was no difference in relative growth between wild and farmed salmon when reared together and separately; (ii) the relative difference in body weight at termination between wild and farmed salmon decreased as mortality increased along the environmental gradient approaching natural conditions.

Conclusions: This study demonstrates that potential social interactions between wild and farmed salmon when reared communally are not likely to cause an overestimation of the genetic growth differences between them. Therefore, common-garden experiments represent a valid methodological approach to investigate genetic differences between wild and farmed salmon. As growth of surviving salmon of all origins became more similar as mortality increased along the environmental gradient approaching natural conditions, a hypothesis is presented suggesting that size-selective mortality is a possible factor reducing growth differences between these groups in the wild.
\end{abstract}

Keywords: Farmed escapees, Hybridization, Introgression, Common-garden, Reaction norm, Inter-strain competition, Heritability

\footnotetext{
*Correspondence: monica.solberg@imr.no

${ }^{1}$ Section of Population Genetics and Ecology, Institute of Marine Research,

P.O. Box 1870, Nordnes, NO-5817 Bergen, Norway

${ }^{2}$ Department of Biology, University of Bergen, P.O. Box 7800 N-5020 Bergen,

Norway

Full list of author information is available at the end of the article
}

\section{Biomed Central}

(c) 2013 Solberg et al.; licensee BioMed Central Ltd. This is an open access article distributed under the terms of the Creative Commons Attribution License (http://creativecommons.org/licenses/by/2.0), which permits unrestricted use, distribution, and reproduction in any medium, provided the original work is properly cited. 


\section{Background}

Hybridization between wild species and their domesticated or hatchery-reared conspecifics constitutes a potential threat to the genetic integrity of natural populations $[1,2]$, and a thorough understanding of the consequences of introgression is crucial for successful conservation of these species. Wild/domesticated hybridization in Atlantic salmon Salmo salar L. is a current concern, due to the large numbers of salmon that escape from the domestic environment each year, and the very high proportions of escapees observed at the spawning grounds in some populations [3]. Although detection of escaped salmon in native populations is not synonymous with introgression $[4,5]$, successful introgression has been documented in rivers in Ireland [6-9], Northeast America [10] and Norway [4,5,11]. In one of the most extensive of these studies [4], two rivers displayed highly significant temporal genetic changes when compared to expected genetic changes based upon simulations [12], which suggest strong introgression of farmed salmon. Recently, cumulative introgression of farmed salmon has also been quantified for the first time in wild populations [5]. Due to the fact that significant genetic differences have been observed between farmed and wild salmon for a range of traits [13-28], it is not surprising that there are significant concerns over the fitness related consequences in native populations where escapees have introgressed [29-32]. Therefore, comparative studies of quantitative traits along the wild/domesticated interface of this species can be used to gain a comprehensive understanding of the evolutionary principles of introgression and hybridization.

Somatic growth in salmonids is a highly polygenic trait [33], and has been the primary target of Atlantic salmon selection programs $[13,34,35]$ since commercial production of this species was initiated in the late 1960's [36]. Selection for increased growth has resulted in domesticated salmon outgrowing wild salmon when studied under standard hatchery conditions [13,15,16,20,28,37-40]. In the most recent growth study, which included the 9-10th generation of domesticated Atlantic salmon, farmed salmon outgrew wild salmon at the freshwater stage at a ratio of 2.9:1 [28]. However, in the wild, domesticated and wild salmon display more similar growth rates $[41,42]$. For example, the 8-9th generation of domesticated salmon, when studied in a natural river, outgrew wild salmon at the most by a ratio of 1.25:1 [41]. So why does farmed salmon outgrow wild salmon extensively in the hatchery, while not in the wild, and are the growth differences detected in the hatchery caused by additive genetic variation?

Social interaction and hierarchies are well documented in salmonids $[43,44]$ where in general bigger and bold fish get better access to feed than smaller and shy fish. As individual differences in growth inflicted by social interaction do not solely reflect genetic differences in growth potential, this could lead to an overestimation of additive genetic variation between salmon of differing strains if they are reared in a communal environment. Comparative studies on the wild/domesticated interface are often performed by the use of common-garden experiments $[16,28,45,46]$, where salmon of all origins are reared together and later assigned to origin by the use of DNA. This approach is often implemented to avoid origin-specific random environmental effects, as could be the case if salmon of differing origin were reared separately. However, as the common-garden design makes it hard to identify confounding effects of social interaction on the traits being studied, e.g., growth, it is valid to ask if the documented differences in growth between farmed and wild salmon are reflected by their additive genetic inheritance for growth or if inter-strain competition is influencing and potentially amplifying the observed growth differences. Would differences in growth between wild and farmed salmon be just as large if salmon of differing origins were reared separately and not communally? In order to answer this question, and to avoid overestimating genetic differences between salmon of wild and domesticated origin, the effect of social interaction and inter-strain competition upon growth in common-garden experiments should be clarified.

Growth rate is an essential factor for an optimal life history strategy in teleosts [47], and while the lack of natural selection in the domestic environment might allow extreme phenotypes to adapt to the predator-free environment, such phenotypes might be maladaptive in the wild and hence selected against, resulting in deviating optimal phenotypes between these environments. The domestic environment deviates from the natural environment in a multitude of ways, as high densities of salmon are reared in a predator-free environment with continuous access to feed. As a result, mortality in the domestic environment is low and mainly assigned to conditions at the site, rearing routines, and disease outbreaks [48]. In contrast, for salmonids in the natural freshwater environment mortality is high, $96.8-99.8 \%$ [14], as a result of natural selective forces, such as predation and competition [49-51]. In the wild, territorial and nutritional competition could be selecting against the slowest growing phenotypes, if small individuals are not gaining access to resources and as a consequence are more vulnerable to starvation, predation and parasites [51-55]. In addition, the risk of predation could be selecting against the fastest growing phenotypes, if they are associated with high-risk behaviour. In contrast, relaxed natural selection in the hatchery combined with directional selection for production related traits, has lead to reduced anti-predator responses in domesticated and hatchery reared salmonids $[16,20,21,56]$ and increased aggressiveness $[16,19,20]$. Thus, it is possible 
that extreme phenotypes are selected against in the wild, reducing the large differences in relative growth rate in wild and farmed salmon that have been observed when they are both reared in the hatchery. Thus, elucidating the competitive balance between wild and domesticated salmon, under different environmental conditions, could benefit towards an understanding of why large difference in growth between wild and domesticated Atlantic salmon are detected in the hatchery environment, but not in the wild.

The present study had two primary aims; (i) investigate if the documented differences in growth between wild and farmed salmon are caused by genetic differences between the strains or influenced by social interaction due to the fact that they are communally reared; (ii) elucidate the competitive balance between wild, hybrid and farmed Atlantic salmon by comparing their norm of reaction for survival and growth along a gradient ranging from a standard hatchery environment to a semi-natural environment with restricted feed. In order to address these objectives, two separate experiments were conducted in 2011/2012. In experiment I, the effect of social interaction and inter-strain competition upon growth in a standard hatchery environment was investigated by comparing the growth of farmed, hybrid and wild salmon when reared together and separately from the eyed-egg stage. In experiment II, the effect of physical environment and nutritional competition on the expression of survival and growth of farmed, hybrid and wild salmon was investigated under standard hatchery conditions, hatchery conditions with restricted access to feed, and in a predator-free semi-natural environment. We predicted intra-strain competition to be as strong as inter-strain competition, and therefore to detect similar relative differences in body weight at termination between wild and domesticated salmon when reared separately and together. Further, we predicted that the relative difference in body weight at termination between surviving wild and domesticated salmon would decrease as the competition level increased along the environmental gradient, while approaching conditions similar to the natural environment.

\section{Methods}

\section{Production of experimental families}

The genetic material used in both experiments was produced in 2010. Wild Atlantic salmon from the river Figgjo $\left(58^{\circ} 47^{\prime} \mathrm{N}, 5^{\circ} 38^{\prime} \mathrm{E}\right)$, and farmed salmon originating from the commercial Mowi strain were used to generate three experimental crosses; (i) ten pure wild families; (ii) ten pure farmed families; (iii) ten $\mathrm{F}_{1}$ hybrid families. Hybrid families were established by crossing farmed females with wild males. Thus the hybrid families were paternal and maternal half-siblings of the farmed and wild families, respectively. This hybrid design was chosen as it resembles the $F_{1}$ hybrid design most likely to be observed in nature [42], and because the farmed salmon were larger and thus more eggs were available to produce both pure and hybrid families. The three experimental groups are from hereon referred to as farmed (Mowi), hybrid (Mowi x Figgjo) and wild (Figgjo).

The Figgjo river has the second largest wild salmon stock in Rogaland, Western Norway, with a female spawning population that exceeds the limit required to attain the rivers estimated carrying capacity $[4,57]$. The Mowi strain is the oldest Norwegian farm strain [36], established from large multi-sea winter fish collected from rivers in Hordaland and Sogn og Fjordane, river Vosso and river Årøy, respectively, as well as salmon caught at sea outside Western Norway [13,22]. The Mowi strain has been selected for increased growth, delayed maturation and fillet quality, in addition to other traits in more recent years [13]. Offspring of the approximately 10th generation were used as parents for the experiments here.

Wild salmon were caught by angling in the river Figgjo on October 15-17, 2010. These were immediately transferred to a local hatchery, and subsequently transported to Matre Research station on October 25, 2010. Unfertilized ova and milt from 10 female and 10 male farmed salmon (c. weight: 12-18 kg) were collected from the Mowi breeding station located at Askøy, and transported to the Matre Research Station. Wild salmon (females: $n=10,2.24 \pm 0.53 \mathrm{~kg}$, mean \pm S.D, males: $n=8$, $1.98 \pm 0.60 \mathrm{~kg}$, mean \pm S.D) were stripped upon arrival of the farmed gametes. All families were established on November 23, 2010, at the Matre Research Station (for family crosses see Additional file 1). From all parental fish adipose fin clips were collected for later parentage testing. Scale samples were also taken from the wild salmon and analysed to confirm that they were not escapees from farms [58].

All 30 families were incubated in single-family units until the eyed-egg stage. Dead eggs were picked daily and then shocked on January 31, 2011, to sort out dead eggs. One wild family was at this point excluded from the study, due to high egg mortality. Hence, the farmed, hybrid and wild origins were represented with 10:10:9 families respectively. Measurement of eggs from all families (diameter in $\mathrm{mm}$ ) were taken on February 18, 2011. On February 22, 2011, fertilized eggs were sorted into the two experiments (Figures 1 and 2).

\section{Experiment I}

In order to investigate the effect of social interaction and inter-strain competition between salmon of wild, hybrid and domesticated origin, salmon families were reared under standard hatchery conditions from the eyed-egg 


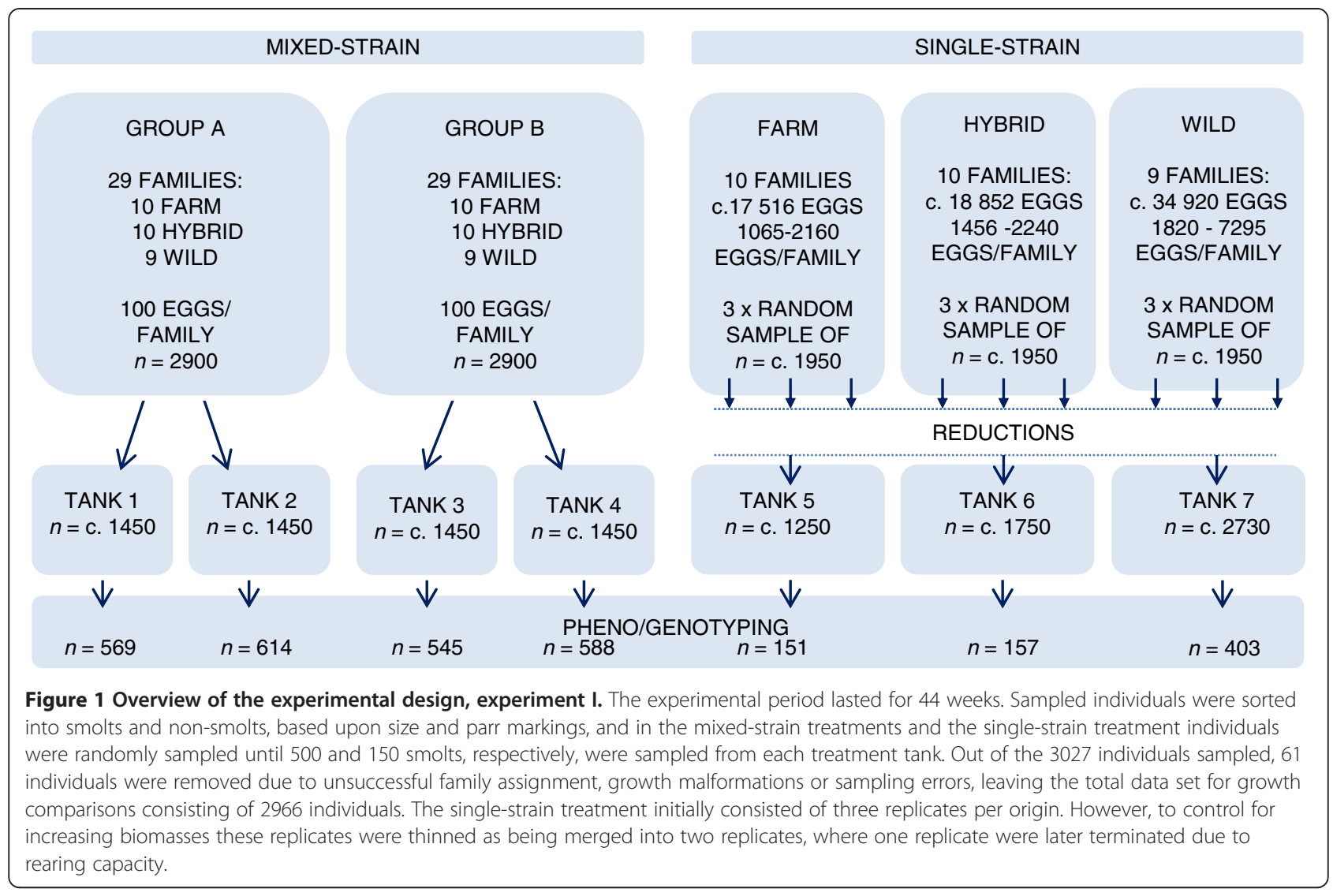

stage in February 2011, until March 2012. They were reared in; (i) mixed-strain tanks or (ii) single-strain tanks. Individual weight measurements upon termination of the experiment were collected in order to investigate the effect of inter-strain competition on growth. These treatments are from here on referred to as the mixed-strain treatment and the single-strain treatment respectively.

Experimental groups were transferred to 1 or $1.5 \mathrm{~m}^{3}$ tanks continuously supplied with fresh water on May 9 , 2011 (for temperatures throughout the experimental period see Additional file 2). From May 10, 2011, fry were presented with commercial fish pellets 24 hours per day by automatic feeders. A standard feeding table for appropriate temperatures was used to calculate the feeding ration, and pellet sizes were adjusted to the mean fish weight, after weighing a sample of 100 individuals per tank. A combination of pellet sizes were used according to supplier's protocol to ensure that all fish were given suitable feed. Experimental groups were from start-feeding onwards kept under 24 hours daily light, until being transferred onto a natural light regime in September 2011. For a schematic overview of the experiment, see Figure 1.

Each of the two replicate groups in the mixed-strain treatment (group A and B) consisted of 100 eggs per family $(n=2900 /$ replicate). Each replicate was initially reared in $1.5 \mathrm{~m}^{3}$ tanks, but due to increasing biomass, each replicate was later transfer to $3 \mathrm{~m}^{3}$ tanks, before being divided in two equal portions (Figure 1). Thus, at the time of sampling, the mixed-strain treatment groups A and B each consisted of two replicates (total $n=4$ ). In the single-strain treatment, eggs from all families of either farmed, hybrid or wild origin (10:10:9 families respectively) were reared together in mixed-family single-strain tanks (Figure 1). Approximately 1950 individuals per origin were randomly sampled in three $1 \mathrm{~m}^{3}$ tank replicates ( $n=5850 /$ strain). These replicates were transferred to three or more $1.5 \mathrm{~m}^{3}$ tanks to account for increasing biomass, and later merged into two $3 \mathrm{~m}^{3}$ tank replicates. Prior to termination of the experiment, one replicate per origin were terminated due to capacity. Thus, at the time of sampling the single-strain treatment consisted of one replicate per origin (Figure 1).

The experiment was terminated on March 14-16 and 19-20, 2012. Thus the experiment lasted for 44 weeks. Upon termination, individuals were sorted into smolts and non-smolts, based upon parr markings and body size. In the mixed-strain treatment, individuals were randomly sampled until 500 smolts were sampled from each of the four replicates. In the single-strain treatment, individuals were randomly sampled until 150 smolts were sampled from each of the three origins. Thus, sample 


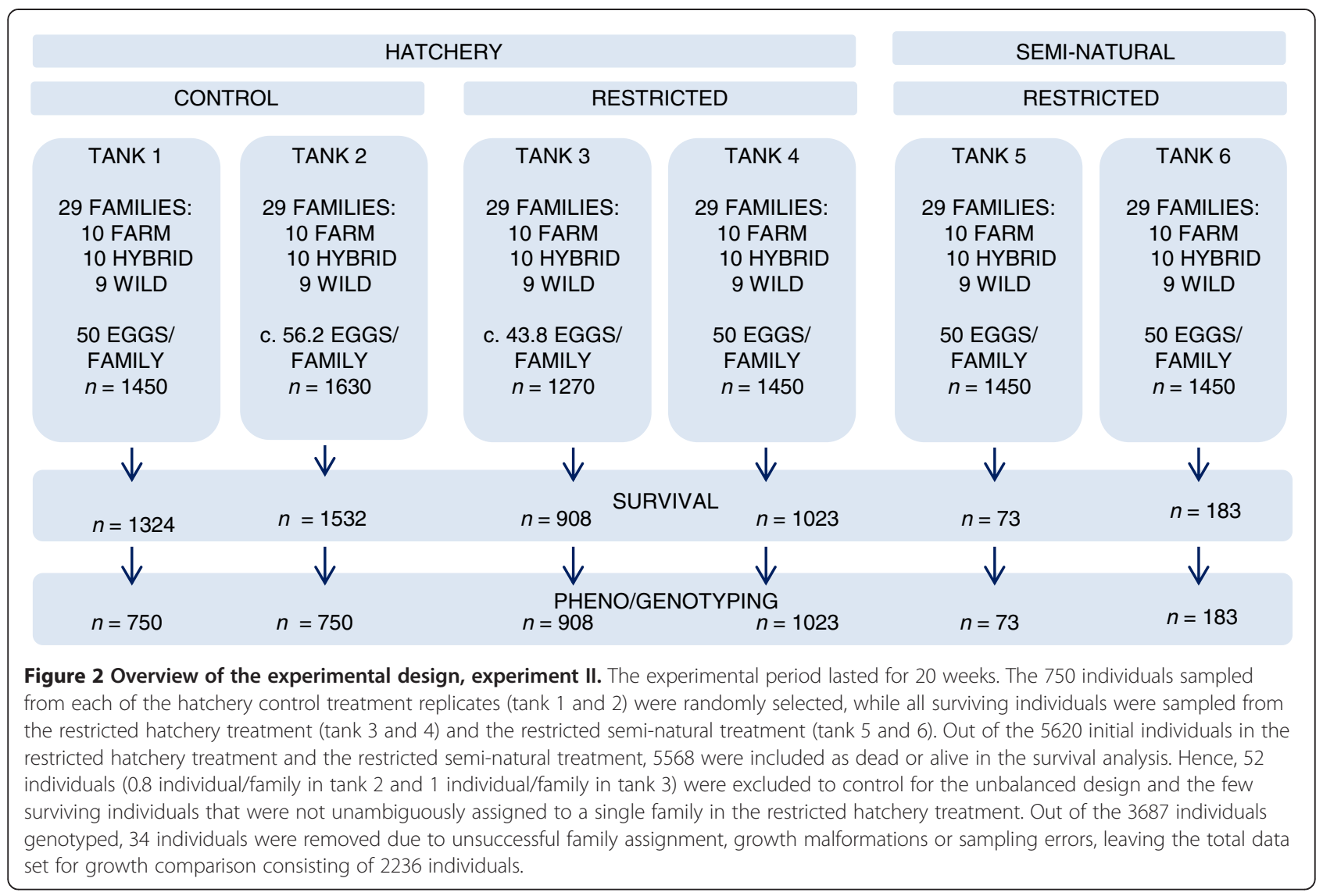

size ranged from 545-614 individuals/tank in the mixedstrain treatment (48-99 individuals/family/treatment), and from 151-403 individuals/tank in the single-strain treatment (7-88 individuals/family/treatment). All sampled individuals were euthanized with an overdose of metacain (Finquel $^{\triangleright}$ Vet, ScanVacc, Årnes, Norway), wet weighed, fork length measured and caudal or adipose fin clipped. Fins were preserved in 95\% ethanol, and all individuals were subsequently assigned to family using six DNA microsatellite markers.

\section{Experiment II}

In order to elucidate the competitive balance between wild, hybrid and domesticated Atlantic salmon at the juvenile stage, salmon families of all origins were reared together from the eyed-egg stage in February 2011, until September 2011. They were reared under; (i) standard hatchery conditions; (ii) hatchery conditions with restricted access to feed and; (iii) in a semi-natural environment with restricted access to feed. Individual weight measurements were collected upon termination of the experiment and absolute or relative survival were recorded in order to examine the effect of nutritional competition between salmon of farmed, hybrid and wild origin in a predator-free environment. These treatments are from hereon referred to as the hatchery control treatment, the restricted hatchery treatment and the restricted semi-natural treatment respectively. For a schematic overview of the experiment see Figure 2.

Eyed eggs were planted in the semi-natural environment on March 10, 2011. The semi-natural environment consisted of a c. $31.4 \mathrm{~m}^{2}$ circular shaped passage (outer radius $3.5 \mathrm{~m}$, inner radius $1.5 \mathrm{~m}$ ), filled with gravel and hiding places. Eggs were planted c. $12 \mathrm{~cm}$ below the gravel, and water level and velocity were modified according to the levels documented at spawning areas of Atlantic salmon [59]. Eggs were planted in Vibert boxes (<500 eggs/box), approximately $3 \mathrm{~m}$ downstream of the water inlet of each tank, thus to ensure sufficient water flow. Automatic feeders were placed immediately beside the water inlet to ensure successful spreading of pellets in the circular tanks.

Rearing conditions of the experimental groups to be reared in the two hatchery treatments were similar to the rearing conditions of experiment I. Thus, start-feeding were initiated on May 10, 2011, while start-feeding in the semi-natural environment was initiated at the corresponding degree day (Table 1). All experimental groups were from start-feeding and throughout the experiment kept under 24 hours daily light. Each replicate initially consisted of 50 eggs per family ( $n=1450 /$ replicate). Upon start of the experimental treatment, approximately 180 
Table 1 Feeding regime, mortality and mean body weight during the experimental period, experiment II

\begin{tabular}{|c|c|c|c|c|c|c|c|c|c|c|c|c|c|c|c|c|c|c|c|c|c|c|c|}
\hline \multirow{3}{*}{$\begin{array}{l}\text { Physical } \\
\text { treatment }\end{array}$} & \multirow[t]{3}{*}{ Tank } & \multirow{3}{*}{$\begin{array}{l}n \\
\text { start }\end{array}$} & \multicolumn{3}{|c|}{$\sim$ week 0} & \multicolumn{4}{|c|}{ Start-feeding (week $0-5)$} & \multicolumn{4}{|c|}{ Week $6-10$} & \multicolumn{4}{|c|}{ Week $11-15$} & \multicolumn{5}{|c|}{ Week 16 - 20 (termination) } & \multirow[t]{3}{*}{$M(\%)$} \\
\hline & & & \multirow[t]{2}{*}{$\bar{M}$} & \multirow[t]{2}{*}{$W(g)$} & \multirow[t]{2}{*}{ DD } & \multirow[t]{2}{*}{$\mathrm{F}(\%)$} & \multirow[t]{2}{*}{$M$} & \multirow[t]{2}{*}{$W(g)$} & \multirow[t]{2}{*}{ DD } & \multirow[t]{2}{*}{$\overline{F(\%)}$} & \multirow[t]{2}{*}{$M$} & \multirow[t]{2}{*}{$W(g)$} & \multirow[t]{2}{*}{ DD } & \multirow[t]{2}{*}{$F(\%)$} & \multirow[t]{2}{*}{$M$} & \multirow[t]{2}{*}{$W(g)$} & \multirow[t]{2}{*}{ DD } & \multirow[t]{2}{*}{$\mathrm{F}(\%)$} & \multirow[t]{2}{*}{$M$} & \multicolumn{2}{|l|}{$W(g)$} & \multirow[t]{2}{*}{ DD } & \\
\hline & & & & & & & & & & & & & & & & & & & & Mean & SD & & \\
\hline Hatchery & 1 & 1450 & 25 & 0.19 & 269 & 110 & 59 & 0.93 & 711 & 110 & 9 & 3.05 & 1128 & 110 & 14 & 9.61 & 1583 & 110 & 19 & 22.78 & 11.76 & 1996 & 8.7 \\
\hline control & 2 & 1630 & 17 & 0.19 & 269 & 110 & 47 & 0.92 & 711 & 110 & 7 & 2.85 & 1128 & 110 & 9 & 10.06 & 1583 & 110 & 18 & 21.66 & 12.03 & 2017 & 6.0 \\
\hline Restricted & 3 & 1270 & 18 & 0.19 & 269 & 75 & 58 & 0.91 & 711 & 25 & 25 & 1.48 & 1128 & 50 & 190 & 3.58 & 1583 & 50 & 71 & 7.76 & 6.3 & 2006 & 28.5 \\
\hline \multirow[t]{4}{*}{ hatchery } & 4 & 1450 & 28 & 0.19 & 269 & 75 & 37 & 0.94 & 711 & 25 & 57 & 1.48 & 1128 & 50 & 239 & 2.71 & 1583 & 50 & 66 & 7.07 & 6.11 & 2028 & 29.4 \\
\hline & & & \multicolumn{3}{|c|}{ Week 1} & \multicolumn{4}{|c|}{ Start-feeding (week 1 - 8) } & Week & -12 & & & Week & $13-1$ & & & Week & $9-20$ & (termina & tion) & & \\
\hline & & & $M$ & $W(g)$ & $\mathrm{DD}$ & $F(\%)$ & $M$ & $W(g)$ & DD & $F(\%)$ & M & $W(g)$ & DD & $F(\%)$ & $M$ & $W(g)$ & DD & $F(\%)$ & $M$ & $W(g)$ & & DD & \\
\hline & & & & & & & & & & & & & & & & & & & & Mean & SD & & \\
\hline Restricted & 5 & 1450 & NA & NA & 269 & 75 & NA & NA & 712 & 25 & NA & NA & 1125 & 25 & NA & NA & 1602 & 25 & 1377 & 11.01 & 5.98 & 1795 & 95.0 \\
\hline semi-natural & 6 & 1450 & NA & NA & 269 & 75 & NA & NA & 712 & 25 & NA & NA & 1125 & 25 & NA & NA & 1602 & 25 & 1267 & 9.08 & 4.51 & 1795 & 87.4 \\
\hline
\end{tabular}

$\mathrm{M}$; mortality ( $n$ ). W; weight (gram). DD; degree day post median time of hatch. F; feeding regime (percent of the recommended feeding regime given by the commercial industry); $\mathrm{M}$ (\%); percentage mortality throughout the experiment. Feed were adjusted once a week in tank $1-4$, while tank 5 and 6 were adjusted at the corresponding degree day. Due to high mortality in the restricted hatchery treatment, the feeding regime was revised in week 11, while kept constant in the restricted semi-natural treatment. Weight measurements during the experimental period is based upon a bulk weight of 100 individuals, while weight at termination is based upon the sampled individuals that were identified to family for further growth comparisons. Initially each tank contained 1450 individuals, while in week 1 , approximately 180 individuals were accidentally transferred from tank 3 to tank 2 during weight measurement. In week 1, mean individual weight in tank $1-4$ was similar (i.e., 0.22 gram). Weight measurements are given for week 5 , 10 , 15 and 20, respectively. 
individuals were accidentally transferred from a restricted hatchery treatment tank $(\operatorname{tank} 3$, mean weight $=$ $0.22 \mathrm{~g} /$ individual) to a hatchery control treatment tank (tank 2 , mean weight $=0.22 \mathrm{~g} /$ individual). This was done in association with weighing fish to enable feeding ration computations. Thus, the four replicates in the hatchery environment were presented by 1450:1630:1270:1450 individuals respectively (Figure 2 ).

The hatchery control treatment $(n=2)$ were reared according to standard hatchery conditions, feed ad libitum by providing a feed ration of $110 \%$ of the recommended ration (Table 1). Salmon in the restricted hatchery treatment $(n=2)$ and the restricted semi-natural treatment $(n=2)$ were given a reduced feed ration, $75 \%$ of the recommended ration during start feeding, then initially $25 \%$ of the recommended ration throughout the remaining experimental period (Table 1). Rations in the hatchery environment were adjusted once a week, while ration in the semi-natural environment was adjusted at the corresponding degree day. Mortality was recorded daily in the hatchery environment, although dead individuals were not assigned to family. Mean fish weight and mortality rates in the restricted hatchery treatment were used as an estimate for feed measurements in the restricted semi-natural treatment. Due to high mortality in the restricted hatchery treatment, feed ration was from week 11 and until termination increased to $50 \%$ of the recommended ration, while ration in the restricted semi-natural treatment was kept constant at $25 \%$ of the recommended ration throughout the experimental period (Table 1).

The experiment was terminated on September 26-30, 2011. Thus the experiment lasted for 20 weeks. In the hatchery control treatment, where mortality was low, 750 individuals were randomly sampled from each of the replicates (Figure 2). All surviving individuals were sampled in the restricted hatchery treatment $(n=908$ and 1023), as well as in the restricted semi-natural treatment ( $n=73$ and 183) (Figure 2). Thus, growth was investigated based upon weight measurement of a representative sample for the control treatment in general, while in the restricted hatchery treatment and the restricted semi-natural treatment only growth of surviving individuals was investigated. All individuals were sampled in the same manner as in experiment I.

\section{Animal ethics}

The experiments were performed in accordance with the general guidelines for animal studies, the Animal Research Reporting In Vivo Experiments (ARRIVE) guidelines [60]. The experimental protocols (permit number 3451 and 4268) were approved by the Norwegian Animal Research Authority (NARA). Welfare and use of experimental animals was performed in strict accordance with the Norwegian Animal Welfare Act of 19th of June 2009, in forced on the 1st of January 2010, while all personnel involved in the experiment had undergone mandatory training approved by the Norwegian Food Safety Authority.

\section{Genotyping and parentage testing}

DNA from a total of 6727 individuals was extracted in 96 well plates using a Qiagen DNeasy 96 Blood \& Tissue Kit, following procedures recommended by the manufacturer. Parental DNA was extracted twice, to ensure correct genotyping. Two randomly assigned blank wells were included on each 96-well plate to ensure a unique identification of the plate. Six microsatellite loci were amplified in one multiplex PCR; SsaF43 [GenBank:U37494] [61], Ssa197 [GenBank:U43694.1] [62], SSsp3016 [GenBank: AY372820], MHCI [63], MHCII [64] and SsOSL85 [GenBank:Z48596.1] [65]. PCR products were analysed on a ABI Applied Biosystems ABI 3730 Genetic Analyser. Genotypes were identified using GeneMapper V4.0., with manual control of scored alleles. All offspring were assigned to family by the use of FAP Family Analysis Program v3.6 [66]. This program has been used on several occasions for parentage testing common-garden studies using these facilities $[28,67,68]$. These genetic markers have revealed very low genotyping errors in this laboratory [69] and are routinely used in association with a genotyping service for the Norwegian legal authorities to identify the farm of origin for escapees $[70,71]$. In order to validate genotyping quality, 77 individuals were randomly selected for re-genotyping, where all gave identical genotype and parentage assignment on the second analysis.

\section{Statistical analyses}

All statistical analyses were performed using $\mathrm{R}$ version 2.15.3 [72], with critical P-values set to 0.05, unless otherwise stated.

\section{Experiment I - growth}

In order to investigate the influence of social interaction and inter-strain competition upon growth in salmon of farmed, hybrid and wild origin, a linear mixed effects (LME) model were fitted using the lmer function in the lme4 package [73]. We first tested for effects of social treatment $(\mathrm{S})$, fish origin $(\mathrm{O})$ and egg size $(\mathrm{E})$ upon body weight at termination $(Y)$, with tank $(\mathrm{t})$ as a random intercept factor nested within group (G) and/or social treatment, while allowing the intercept of families (f) to randomly vary across treatments, i.e., random slope $(\mathrm{f} S)$. All interaction terms between the fixed effects were included in the full model;

$$
\begin{aligned}
Y= & \alpha+\beta_{1} S+\beta_{2} O+\beta_{3} E+\beta_{4} S O+\beta_{5} S E+\beta_{6} O E+\beta_{7} S O E \\
& +b_{t((\mathrm{G}) \mathrm{S})}+b_{f}+b_{f} S+\varepsilon(1 \text { Full })
\end{aligned}
$$

where $\varepsilon$ is a random error. The response variable, i.e., body weight at termination, was $\log$-transformed $\left(\log _{10}\right)$, as the 
difference in weight between treatment $y$ (e.g., mixedstrain treatment) and $x$ (e.g., single-strain treatment) of value $z$ will equal a greater portion of the weight in treatment $y$ if the value of $y$ is small than if it is large [74-76]. A constant was added so that all values of the response variable were above 1 prior to the transformation.

Model selection were performed by first including fixed effects of the full model in a linear model, then random effect structures were added and the best structure identified based upon Akaike Information Criterion (AIC) values, while using Restricted Maximum Likelihood (REML) estimators [77]. Once the random effect structure were identified, the fixed effect structure were fitted by backward selection based upon AIC values, while using Maximum Likelihood (ML) estimators [77]. Models displaying AIC values of \pm 2 were considered equally good and by the principle of parsimony, the simplest model that performed best were selected. Thus, insignificant variables were removed from the model, interaction terms before the variables themselves, until no further improvement of the model fit were detected;

$$
Y=\alpha+\beta_{1} S+\beta_{2} O+\beta_{3} S O+b_{t((G) S)}+b_{f}+\varepsilon(1 \text { Selected })
$$

For AIC comparisons of the LME model, see Additional file 3. For parameter estimates of the selected model fitted using REML estimation, i.e., $t$-statistics retrieved from the summary output of the LME, see Additional file 4. $\mathrm{P}$-values of the fixed effects were calculated from the F-statistics of the selected LME model, fitted using ML estimation. The F-value and the numerator degrees of freedom ( $k-1$, where $k$ is the number of factor levels) were retrieved from the anova output of the LME model. Denominator degrees of freedom were calculated as N-k, where $\mathrm{N}$, conservatively, was set to the smallest sample size detected in any of the three origins in any of the two treatments. Differences in performance between salmon of specific origins were estimated by re-running the selected model while excluding one of the three genetic origins at a time (see Additional file 5). Multiple comparisons were corrected for by the Bonferroni correction, giving an adjusted significance level of $0.017(\alpha=\mathrm{P} / 3)$.

In order to investigate stability of family performance across social treatments, Pearson correlations were conducted between mean family $\log _{10}$-weight in the mixedstrain treatment and the single-strain treatment. Pearson correlation tests were performed separately for each origin, and the single-strain replicate were compared to each of the four mixed-strain replicates.

\section{Experiment II - growth}

In order to investigate the influence of physical environment and nutritional competition upon growth of surviving farmed, hybrid and wild salmon, linear mixed effects (LME) models were fitted pair wise for the three physical treatments constituting the environmental gradient, i.e., three models in total. We first tested for effects of physical treatment $(\mathrm{P})$, fish origin $(\mathrm{O})$ and egg size (E) upon body weight at termination $(Y)$, with tank $(t)$ as a random intercept factor nested within physical treatment, while allowing the intercept of families (f) to randomly vary across treatments, i.e., random slope $\left({ }_{\mathrm{f}} \mathrm{P}\right)$. All interaction terms between the fixed effects were included in the full model;

$$
\begin{aligned}
Y= & \alpha+\beta_{1} P+\beta_{2} O+\beta_{3} E+\beta_{4} P O+\beta_{5} P E+\beta_{6} O E+\beta_{7} P O E \\
& +b_{t(P)}+b_{f}+b_{f} P+\varepsilon(2.1-2.3 \text { Full })
\end{aligned}
$$

where $\varepsilon$ is a random error. The response variable, i.e., body weight at termination, was $\log$-transformed $\left(\log _{10}\right)$, while a constant were added prior to the transformation. Model selection was performed as described above by removing insignificant variables until no further improvement of the model fits were detected;

$$
Y=\alpha+\beta_{1} P+\beta_{2} O+\beta_{3} P O+b_{t(P)}+b_{f}+b_{f} P+\varepsilon(2.1 \text { Selected })
$$

when fitted for salmon in the hatchery control treatment and the restricted hatchery treatment;

$$
Y=\alpha+\beta_{1} P+\beta_{2} O+\beta_{3} P O+b_{t(P)}+b_{f}+\varepsilon(2.2 \text { Selected })
$$

when fitted for salmon in the hatchery control treatment and the restricted semi-natural treatment;

$$
Y=\alpha+\beta_{1} P+\beta_{2} O+b_{t(P)}+b_{f}+b_{f} P+\varepsilon(2.3 \text { Selected })
$$

when fitted for salmon in the restricted hatchery treatment and the restricted semi-natural treatment.

For AIC comparisons of the LME models and parameter estimates of the selected models, see Additional files 3 and 4. Calculation of P-values of the fixed effects and investigation of performance of salmon of specific origins (see Additional file 5) were performed as described above.

In order to investigate stability in family performance across the physical hatchery environments, Pearson correlations were performed between mean family $\log _{10^{-}}$ weight in the hatchery control treatment and the restricted hatchery treatment. Again, Pearson correlation tests were performed separately for each origin, and both replicates in the hatchery control treatment were compared to the two replicates in the restricted hatchery treatment. Pearson correlation tests were not performed across the restricted semi-natural treatment, due to the small sample size of some families.

\section{Experiment II - sampling and mortality}

In order to test for differences in observed mortality between the replicates in the hatchery control treatment, 
as well as to test for differences in sampling frequency of farmed, hybrid and wild salmon within the hatchery control subsamples, chi-square $\left(x^{2}\right)$ tests for given probabilities, based upon numbers, was performed.

In order to investigate the influence of different effects upon survival in the restricted hatchery treatment and the restricted semi-natural treatment where exact mortality was known, a generalized linear mixed effect model (GLMM) was fitted using the lmer function in the lme4 package [73]. We first tested for effects of physical treatment $(\mathrm{P})$, origin $(\mathrm{O})$ and egg size $(\mathrm{E})$ upon survival $(\mathrm{Y})$, with tank $(\mathrm{t})$ as a random intercept factor nested within physical treatment, while allowing the intercept of families (f) to randomly vary across treatments, i.e., random slope $\left({ }_{\mathrm{f}} \mathrm{P}\right)$. All interaction terms between the fixed effects were included in the full model:

$$
\begin{aligned}
\operatorname{logit}(\mathrm{Y})= & \alpha+\beta_{1} P+\beta_{2} O+\beta_{3} E+\beta_{4} P O+\beta_{5} P E+\beta_{6} O E \\
& +\beta_{7} P O E+b_{t(P)}+b_{f}+b_{f} P+\varepsilon(3 \text { Full })
\end{aligned}
$$

where $\varepsilon$ is a random error. Due to survival being binary data, the binomial distribution was selected with a logit link function, and models were fitted using the Laplace approximation. Identification of the random effect structure was done by performing likelihood ratio tests (LRT) on the full fixed effects model. Then the fixed effects structure were identified by backward model selection, based upon AIC values [78]. Thus, insignificant variables were removed from the model, interaction terms before the variables themselves, until no further improvement of the model fit were detected:

$$
\begin{aligned}
\operatorname{logit}(\mathrm{Y})= & \alpha+\beta_{1} P+\beta_{2} O+\beta_{3} E+b_{t(P)}+b_{f} \\
& +b_{f} P+\varepsilon(3 \text { Selected })
\end{aligned}
$$

For model selection of the GLMM, see Additional file 6 . Parameter estimates from the selected model were obtained by performing a Wald $Z$-test. Differences in probability of survival between salmon of specific origins were estimated by re-running the final model while excluding one of the three genetic origins at a time (see Additional file 7). Multiple comparisons were corrected for by the Bonferroni correction, giving an adjusted significance level of 0.017 . To control for the unbalanced design and the few surviving individuals that were not unambiguously assigned to a single family in the restricted hatchery treatment, the estimated sample size per family was set to 43 individuals in tank 3 and 49 individuals in tank 4 (see Figure 2).

\section{Heritability of body weight (experiment I and II)}

In order to investigate the portion of phenotypic variance attributed to genetic variation in salmon of farmed, hybrid and wild origin, heritability $h^{2}$ of body weight $\left(\log _{10}\right)$ was calculated as;

$$
h^{2}=\mathrm{V}_{\mathrm{A}} / \mathrm{V}_{\mathrm{P}},
$$

where $V_{A}$ is the additive genetic variance and $V_{P}$ is the phenotypic variance. Heritability estimates was calculated in the mixed-strain treatment of experiment I and in the hatchery control treatment and the restricted hatchery treatment of experiment II. To control for halfsibling families within the genetic origins, variance components were estimated from the pedigree of the data by fitting a generalized linear mixed model using Markov chain Monte Carlo methods (MCMCglmm) from the MCMCglmm package [79], i.e., the animal model $[80,81]$. One model was fitted per origin, per treatment, i.e., nine models in total. The full model included the fixed effect of egg size (E) upon body weight $\left(\log _{10}\right)$ at termination (Y), with tank (t) and Animal (a) as random intercept effects:

$$
Y=\alpha+\beta_{1} E+b_{t}+b_{a}+\varepsilon(4.1-4.9 \text { Full })
$$

where $\varepsilon$ is a random error. Animal (a) is the additive genetic merit of an individual, i.e., the breeding value $[80,81]$. Thus, $\mathrm{V}_{\mathrm{A}}$ is the estimated variance in breeding values [80]. The fixed effect egg size was not considered significant in any of the model as its posterior distribution overlapped zero [80], while model selection on the random effect structure, by the use of the Deviance Information Criterion (DIC), revealed significant tank effects in all experimental groups (for DIC comparisons see Additional file 8):

$$
Y=\alpha+b_{t}+b_{a}+\varepsilon(4.1-4.9 \text { Selected })
$$

Weakly informative priors for the animal model were generated by equally partitioning phenotypic variance $\left(V_{\mathrm{P}}\right)$ into the genetic and residual components, while placing little weight on the values specified by the priors, i.e., with a low degree of belief [80]. Priors with stronger degree of belief and with different partitioning of the phenotypic variance between the components were also tested. We settled on the weakly informative priors yielding conservative heritability estimates. Each model was run for 8,000,000 iterations with the first 300,000 iterations excluded as burn-in, and was thereafter sampled every 7000 iterations. Convergence of the model was checked by calculating autocorrelations among the samples of the posterior distributions [80]. As a measure of precision of the heritability estimates, credibility intervals were calculated as $95 \%$ highest posterior density (HPD) intervals using the HPDinterval function in the lme4 package [73]. 


\section{Results}

Experiment I - the effect of inter-strain competition upon growth

\section{Genotyping and parentage testing}

Out of the 3027 individuals sampled, 25 individuals were not selected for parental assignment due to a documented sampling error. A further 13 individuals were not assigned to family, either due to overlapping composite genotypes between family pairs, or due to genotyping errors. Thus, a total of 2989 individuals were unambiguously assigned to family. After parental assignment, 23 individuals were identified as outliers and post hoc excluded from the data set. These individuals displayed growth malformations and/or extreme condition factor values. The final data set consisted of 2966 individuals.

\section{Growth in mixed-strain and single-strain tanks}

In general, body weight of all salmon was significantly higher in the mixed-strain treatment than in the singlestrain treatment (Tables 2 and 3; Figure 3). Farmed salmon were significantly larger than wild salmon, and hybrids displayed intermediate growth that was significantly different to both the farmed and wild salmon (Tables 2 and 3; Figure 3).

In general, farmed and wild salmon displayed similar growth reaction norm slopes between the mixed-strain treatment and the single-strain treatment, only differing in elevation (Table 3; Figure 4; Additional file 5). Thus, the relative difference in weight between wild and farmed salmon were similar both when reared together and when reared separately. In general, the slopes displayed by the hybrid salmon were significantly flatter than the slopes displayed by both the farmed and wild salmon (Table 3; Figure 4; Additional file 5). Heterogeneity of variance among tanks (see Additional file 9) and families was detected and controlled for in the final LME model, while families did not differ in their variance across the two rearing treatments (Additional file 3). Egg size did not have a significant effect upon body weight at termination, thus the inclusion of egg size in the final LME models did not improve the fit (Additional file 3).

No overlap in mean family weight between the wild, hybrid and farmed salmon families were detected in the mixed-strain treatment, nor in the single-strain treatment (Figure 3). A significant correlation between mean family weight in the mixed-strain treatment and mean family weight in the single-strain treatment were detect in salmon of all origins (Wild: $n=36$, Pearson $r=0.91$, $\mathrm{P}<0.0001$; Hybrid: $n=40$, Pearson $\mathrm{r}=0.67, \mathrm{P}<0.0001$; Farm: $n=40$, Pearson $r=0.61, \mathrm{P}<0.0001$; Figure 4).

\section{Experiment II - survival and growth along an environmental gradient}

\section{Genotyping and parentage testing}

Of the 3687 fish sampled for parental assignment, 3672 were unambiguously identified to family. Hence, 15 individuals were not assigned to family, either due to overlapping composite genotypes between family pairs, or due to genotyping errors. These individual were removed from the data set. A further 19 individuals were post hoc excluded from

Table 2 Weight measurements of Salmo salar L. of farmed, hybrid and wild origin, experiment I

\begin{tabular}{|c|c|c|c|c|c|c|c|c|c|c|c|c|c|}
\hline \multirow{2}{*}{$\begin{array}{l}\text { Social } \\
\text { treatment }\end{array}$} & \multirow[t]{2}{*}{ Origin } & \multirow[t]{2}{*}{ Group } & \multirow[t]{2}{*}{ Tank } & \multirow[t]{2}{*}{$n$} & \multicolumn{3}{|c|}{$W(g)$} & \multicolumn{3}{|c|}{$\mathrm{L}(\mathrm{cm})$} & \multicolumn{3}{|c|}{$\mathrm{K}$} \\
\hline & & & & & Mean & Median & SD & Mean & Median & SD & Mean & Median & SD \\
\hline \multirow[t]{12}{*}{ Mixed-strain } & Farm & A & 1 & 211 & 93.84 & 91 & 23.6 & 19.44 & 19.4 & 1.75 & 1.25 & 1.2 & 0.07 \\
\hline & & A & 2 & 170 & 94.22 & 92 & 26.2 & 19.49 & 19.5 & 1.85 & 1.24 & 1.2 & 0.07 \\
\hline & & B & 3 & 173 & 96.84 & 94 & 23.77 & 19.74 & 19.7 & 1.58 & 1.24 & 1.2 & 0.08 \\
\hline & & $B$ & 4 & 149 & 96.16 & 95 & 23.16 & 19.58 & 19.5 & 1.71 & 1.26 & 1.3 & 0.07 \\
\hline & Hybrid & $A$ & 1 & 211 & 50.73 & 52 & 15.46 & 15.75 & 16.1 & 1.79 & 1.25 & 1.2 & 0.07 \\
\hline & & $A$ & 2 & 208 & 48.99 & 49 & 13.67 & 15.7 & 15.9 & 1.7 & 1.22 & 1.2 & 0.07 \\
\hline & & $B$ & 3 & 205 & 52.54 & 54 & 15.66 & 16.12 & 16.6 & 1.89 & 1.21 & 1.2 & 0.1 \\
\hline & & $B$ & 4 & 208 & 51.25 & 51.5 & 15.76 & 15.91 & 16.2 & 1.93 & 1.23 & 1.2 & 0.1 \\
\hline & Wild & $A$ & 1 & 144 & 18.61 & 14.5 & 11.61 & 11.13 & 10.45 & 2.24 & 1.16 & 1.2 & 0.13 \\
\hline & & A & 2 & 233 & 18.65 & 14 & 11.72 & 11.17 & 10.5 & 2.42 & 1.16 & 1.2 & 0.13 \\
\hline & & B & 3 & 125 & 21.94 & 24 & 12.13 & 11.82 & 12.4 & 2.41 & 1.16 & 1.2 & 0.11 \\
\hline & & $B$ & 4 & 222 & 19.18 & 17 & 11.5 & 11.2 & 10.8 & 2.24 & 1.19 & 1.2 & 0.13 \\
\hline \multirow[t]{3}{*}{ Single-strain } & Farm & NA & 5 & 150 & 74.99 & 72 & 23.12 & 17.98 & 18.05 & 1.93 & 1.24 & 1.2 & 0.07 \\
\hline & Hybrid & NA & 6 & 154 & 47.35 & 47 & 12.62 & 15.57 & 15.65 & 1.5 & 1.22 & 1.2 & 0.1 \\
\hline & Wild & NA & 7 & 403 & 14.56 & 10 & 10.04 & 10.44 & 9.7 & 2.23 & 1.08 & 1.1 & 0.13 \\
\hline
\end{tabular}


Table 3 Summary of the LME models testing for differences in weight $\left(\log _{10}\right)$ at termination, experiment I and II

\begin{tabular}{|c|c|c|c|c|c|c|c|c|}
\hline Experiment & Model & Social or physical treatment & Fixed effect & DFn & DFd & Sum Sq & $\mathbf{F}$ & $\mathbf{P}$ \\
\hline \multirow[t]{3}{*}{ I } & \multirow[t]{3}{*}{1} & \multirow[t]{3}{*}{ Mixed-strain vs. single-strain } & Social treatment & 1 & 148 & 0.9 & 28.3 & $<0.0001$ \\
\hline & & & Origin & 2 & 147 & 7.4 & 114.7 & $<0.0001$ \\
\hline & & & Social treatment $x$ origin ${ }^{1}$ & 2 & 147 & 0.3 & 4.8 & 0.017 \\
\hline \multirow[t]{8}{*}{$\|$} & \multirow[t]{3}{*}{2.1} & \multirow{3}{*}{$\begin{array}{l}\text { Hatchery control vs. } \\
\text { restricted hatchery }\end{array}$} & Physical treatment & 1 & 425 & 6.1 & 157.9 & $<0.0001$ \\
\hline & & & Origin & 2 & 424 & 9.1 & 117.7 & $<0.0001$ \\
\hline & & & Physical treatment $x$ origin ${ }^{2}$ & 2 & 424 & 0.9 & 11.5 & $<0.0001$ \\
\hline & \multirow[t]{3}{*}{2.2} & \multirow{3}{*}{$\begin{array}{l}\text { Hatchery control vs. } \\
\text { restricted semi-natural }\end{array}$} & Physical treatment & 1 & 35 & 2.0 & 99.2 & $<0.0001$ \\
\hline & & & Origin & 2 & 34 & 4.7 & 118.0 & $<0.0001$ \\
\hline & & & Physical treatment $\mathrm{x}$ origin & 2 & 34 & 1.3 & 32.3 & $<0.0001$ \\
\hline & \multirow[t]{2}{*}{2.3} & \multirow{2}{*}{$\begin{array}{l}\text { Restricted hatchery vs. } \\
\text { restricted semi-natural }\end{array}$} & Physical treatment & 1 & 35 & 0.6 & 11.0 & 0.0009 \\
\hline & & & Origin & 2 & 34 & 4.6 & 43.7 & $<0.0001$ \\
\hline
\end{tabular}

F-statistics of the selected linear mixed effects models, fitted using ML estimation. DFn; numerator degrees of freedom. DFd; denominator degrees of freedom. Differences in body weight at termination between salmon of farmed, hybrid or wild origin were investigated by re-running the selected models while excluding one of the three genetic origins at a time, while multiple comparisons were corrected for by the Bonferroni correction, giving an adjusted significance level of 0.017 . $^{1}$ The interaction treatment $x$ origin were not significant in the farmed and wild salmon $(D F n=1, D F d=148, S u m ~ S q=0.0006, F=0.015, P=1) .{ }^{2}$ The interaction treatment $x$ origin were not significant in the hybrid and farmed salmon (DFn $=1, D F d=425, S u m ~ S q=0.0014, F=0.036, P=1$ ).

the growth analysis. Of these 19 individuals, 9 displayed growth malformation and/or extreme condition factor values, while 10 individuals were excluded due to a documented sampling error. Thus, the growth analyses were based upon 3653 individuals in total.

\section{Mortality and sampling}

Mortality was low in the control treatment throughout the experimental period (Table 1). Variation in mortality between replicates were detected $\left(x^{2}=7.56, \mathrm{df}=1, \mathrm{P}=0\right.$. 006; Table 1). However, in the subsample from each tank $(n=750)$, salmon of all origins were represented within their expected frequencies (Tank $1: x^{2}=5.17, \mathrm{df}=2$, $\mathrm{P}=0.08$; Tank 2: $x^{2}=1.47, \mathrm{df}=2, \mathrm{P}=0.48$; Figure 5), as expected if mortality and sampling were random.

In the restricted hatchery and restricted semi-natural treatments, all surviving individuals were identified to family, thus origin-specific mortality was estimated from the total sample size (adjusted $n=5568$ ). For salmon of all origins, survival was lower in the restricted semi-natural treatment, compared to in the restricted hatchery treatment (Tables 4 and 5; Figure 5). In both treatments, survival was lower in the wild salmon, while hybrid and farmed salmon displayed higher and insignificantly different survival (Tables 4 and 5; Figure 5). Thus, no significant genotype-by-environment effect upon survival across the restricted hatchery treatment and the restricted semi-natural treatment was detected (Additional file 6).

A positive effect of egg size on survival was detected in the restricted hatchery and restricted semi-natural treatments (Table 5; Figure 6). Thus in general, individuals originating from families with high mean egg size had a higher survival than individuals emerging from families with low mean egg size. When corrected for multiple comparisons, the effect of egg size on survival was no longer significant in the farmed and hybrid salmon $(\mathrm{P}=0.019$, Bonferroni $\mathrm{P}=0.017)$, where survival was highest and variation in egg size smallest (Additional file 7).

Heterogeneity of variance in survival between replicate tanks, and among families across treatments was detected and controlled for in the final GLMM (see Additional file 6; Figure 6).

\section{Influence of treatment on body weight at termination}

Fish size upon termination of the experiment was significantly higher in the hatchery control treatment than in the restricted hatchery treatment and the restricted semi-natural treatment (Tables 3 and 4; Figure 7). Fish size was significantly higher in the restricted semi-natural treatment than in the restricted hatchery treatment, despite the fact that fewer degree days had elapsed in the restricted semi-natural treatment upon termination (Tables 1, 3 and 4; Figure 7). Thus, the general growth reaction norm slope between the hatchery control treatment and both the restricted hatchery treatment and the restricted semi-natural treatment was negative, while the slope between the restricted hatchery treatment and the semi-natural treatment was positive (Figure 8).

Where heterogeneity of variance in body weight at termination between replicate tanks, among families, and among families across treatments was detected, it was 

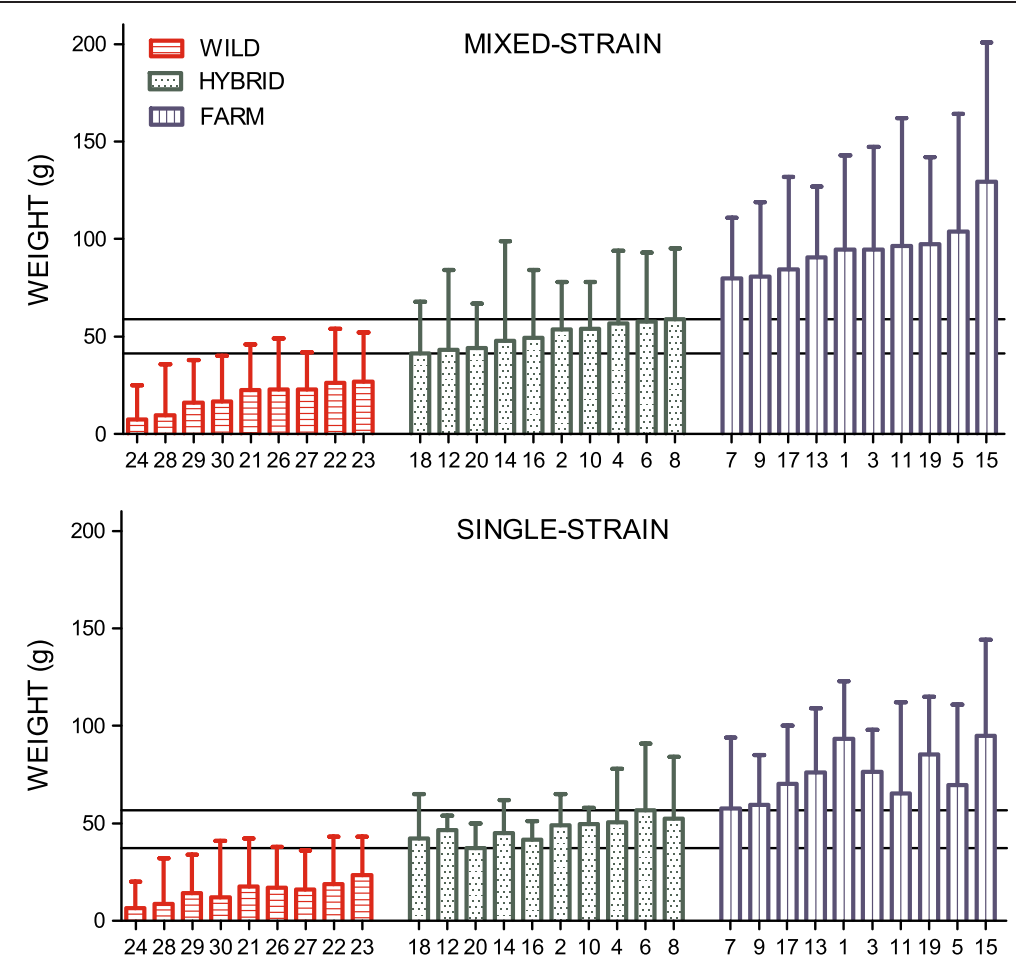

FAMILY

Figure 3 Mean family weight of salmon of all origin reared separately and together, experiment I. Mean family weight (g) of the farmed, hybrid and wild families reared in the mixed-strain treatment and the single-strain treatment. Replicated tanks in the mixed-strain treatment are pooled. Growth was significantly lower in the single-strain treatment; however relative weight between wild and farmed salmon were similar in both treatments. There is no overlap in mean family weight of the wild, hybrid and farmed families in any of the treatments. Families are ranked by their mean family weight in the pooled mixed-strain treatment, by increasing order. Lines represent the mean of the smallest and largest hybrid family within each treatment. Error bars show the range. See Additional file 9 for mean family weight in all four mixed-strain replicates.

controlled for in the final LME model (see Additional file 3). Egg size did not have a significant effect upon body weight at termination, thus the inclusion of egg size in the final LME models did not improve the fit (Additional file 3).
Influence of fish origin (farmed/hybrid/wild) on body weight at termination

Body weight of all three experimental groups was significantly different to each other, in all treatments. Farmed salmon were significantly larger than the wild salmon,

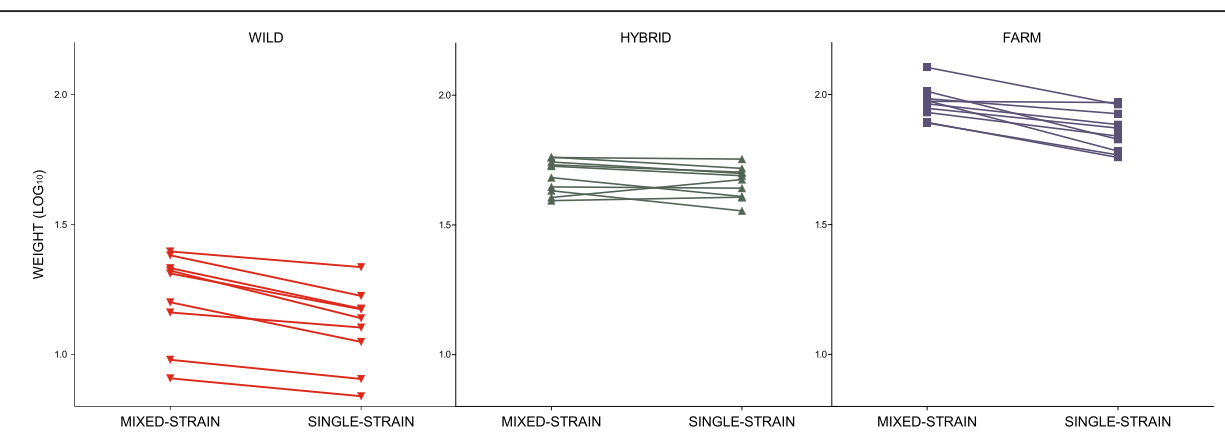

Figure 4 Growth reaction norms between the mixed-strain treatment and single-strain treatment, experiment I. Family weight (log 10$)$ norm of reaction between the two rearing treatments, for salmon of farmed, hybrid and wild salmon. Replicated tanks are pooled. Fish sizes were significantly higher in the mixed-strain treatment than in the single-strain treatment, and the elevation of the reaction norms were significantly different between salmon of farmed, hybrid and wild origin. The slopes between treatments were similar in the wild and farmed salmon, while the flatter slopes displayed by the hybrid salmon were significantly different to the slopes displayed by both the farmed and wild salmon. A significant correlation between mean family weight in the mixed-strain treatment and mean family weight in the single-strains treatment were detected in salmon of all origin. 


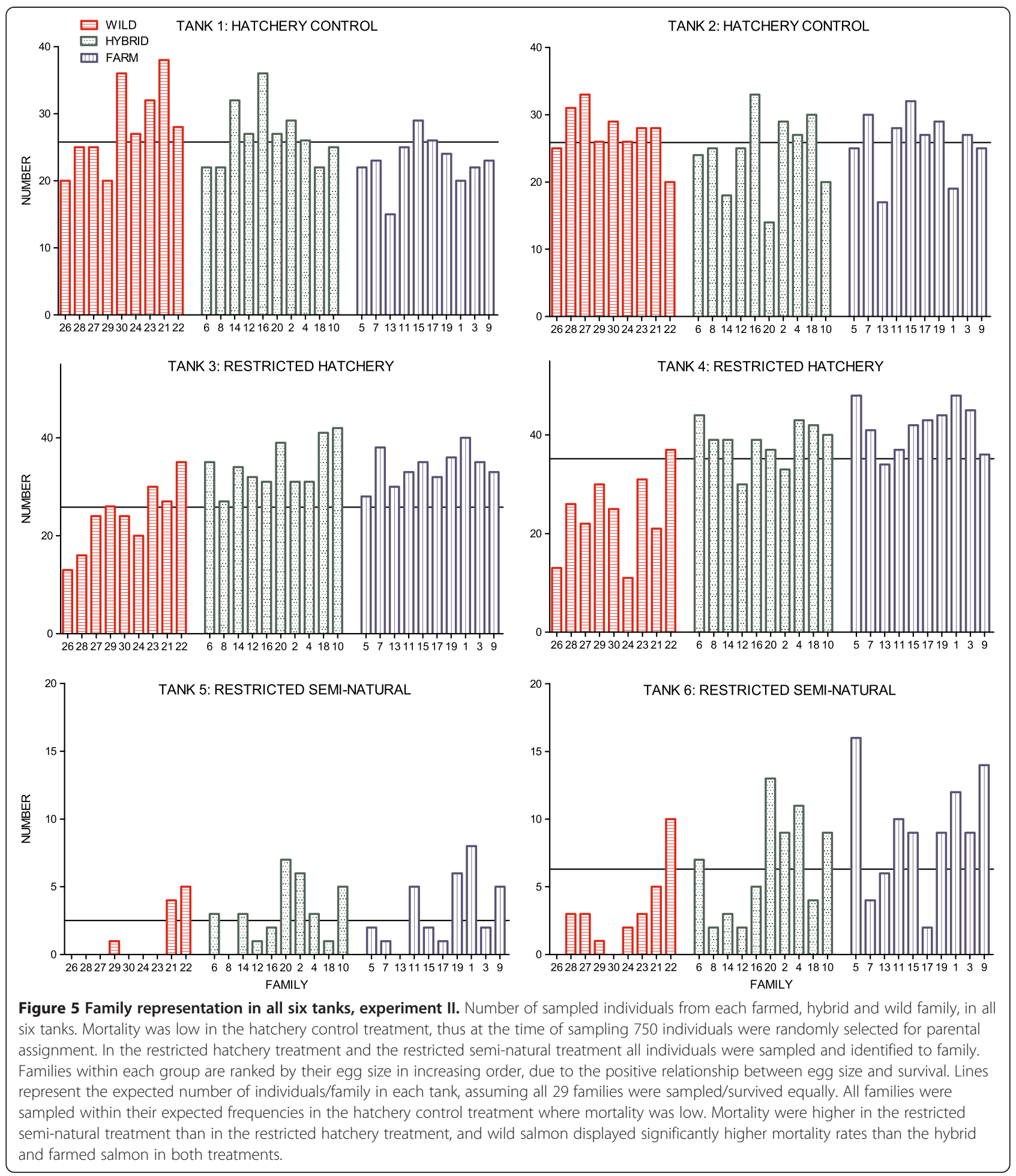

and hybrids displayed an intermediate body weight that was significantly different to both the farmed and the wild salmon (Tables 3 and 4; Figure 7). Thus the elevation of the growth reaction norms across treatments was significantly different in the three experimental groups (Figure 8).
Significant genotype-by-environment interactions were detected between the hatchery control treatment and both the restricted hatchery treatments and the restricted semi-natural treatment (Table 3). Thus, salmon of farmed, hybrid or wild origin displayed significantly different growth reaction norm slopes. Wild salmon 
Table 4 Weight measurements of Salmo salar. L of wild, hybrid and farmed origin, experiment II

\begin{tabular}{|c|c|c|c|c|c|c|c|c|c|c|c|c|c|c|c|c|c|c|c|}
\hline \multirow[t]{2}{*}{ Physical treatment } & \multirow[t]{2}{*}{ Origin } & \multirow[t]{2}{*}{ Tank } & \multirow[t]{2}{*}{$n$} & \multicolumn{3}{|c|}{$W(g)$} & \multicolumn{3}{|c|}{$\mathrm{L}(\mathrm{cm})$} & \multicolumn{3}{|c|}{$\mathrm{K}$} & \multicolumn{4}{|c|}{ W (g) } & \multicolumn{2}{|c|}{ Weight difference } & \multirow{2}{*}{$\begin{array}{c}\text { Mortality } \\
\%\end{array}$} \\
\hline & & & & Mean & Median & $\overline{S D}$ & Mean & Median & $\overline{S D}$ & Mean & Median & SD & $n$ & Mean & Median & $\overline{S D}$ & Absolute (g) & $\%$ & \\
\hline \multirow[t]{6}{*}{ Hatchery control } & Farm & 1 & 227 & 35.94 & 35.0 & 7.85 & 13.98 & 14.00 & 0.97 & 1.29 & 1.30 & 0.07 & 486 & 35.23 & 35.0 & 7.43 & NA & NA & NA \\
\hline & & 2 & 259 & 34.61 & 35.0 & 7.01 & 13.77 & 13.90 & 0.96 & 1.30 & 1.30 & 0.08 & & & & & & & \\
\hline & Hybrid & 1 & 266 & 22.35 & 23.0 & 5.85 & 11.98 & 12.10 & 1.06 & 1.26 & 1.30 & 0.07 & 509 & 21.43 & 22.0 & 5.92 & NA & NA & NA \\
\hline & & 2 & 243 & 20.43 & 21.0 & 5.85 & 11.61 & 11.80 & 1.12 & 1.26 & 1.30 & 0.07 & & & & & & & \\
\hline & Wild & 1 & 251 & 11.31 & 11.0 & 5.42 & 9.50 & 9.50 & 1.51 & 1.21 & 1.22 & 0.10 & 497 & 10.28 & 9.0 & 5.14 & NA & NA & NA \\
\hline & & 2 & 246 & 9.23 & 8.0 & 4.63 & 8.92 & 8.80 & 1.36 & 1.19 & 1.20 & 0.12 & & & & & & & \\
\hline \multirow[t]{6}{*}{ Restricted hatchery } & Farm & 3 & 338 & 11.28 & 9.0 & 7.47 & 9.37 & 9.10 & 2.02 & 1.18 & 1.20 & 0.11 & 753 & 10.77 & 9.0 & 7.38 & 24.46 & 69.4 & 18.2 \\
\hline & & 4 & 415 & 10.35 & 9.0 & 7.28 & 9.11 & 9.10 & 2.06 & 1.14 & 1.20 & 0.14 & & & & & & & \\
\hline & Hybrid & 3 & 339 & 6.61 & 5.0 & 4.65 & 7.94 & 7.50 & 1.59 & 1.14 & 1.20 & 0.14 & 725 & 6.02 & 4.0 & 4.35 & 15.42 & 71.9 & 21.2 \\
\hline & & 4 & 386 & 5.50 & 4.0 & 4.01 & 7.54 & 7.20 & 1.61 & 1.07 & 1.10 & 0.18 & & & & & & & \\
\hline & Wild & 3 & 212 & 3.97 & 3.0 & 2.66 & 6.84 & 6.55 & 1.17 & 1.10 & 1.10 & 0.16 & 427 & 3.77 & 3.0 & 2.73 & 6.51 & 63.3 & 48.4 \\
\hline & & 4 & 215 & 3.57 & 3.0 & 2.80 & 6.69 & 6.50 & 1.36 & 1.00 & 1.10 & 0.23 & & & & & & & \\
\hline \multirow[t]{6}{*}{ Restricted semi-natural } & Farm & 5 & 32 & 13.59 & 12.5 & 6.98 & 10.00 & 10.10 & 1.86 & 1.23 & 1.20 & 0.09 & 123 & 11.85 & 11.0 & 5.38 & 23.39 & 66.4 & 87.7 \\
\hline & & 6 & 91 & 11.23 & 11.0 & 4.58 & 9.67 & 9.80 & 1.40 & 1.16 & 1.20 & 0.10 & & & & & & & \\
\hline & Hybrid & 5 & 31 & 9.81 & 8.0 & 4.18 & 9.10 & 9.00 & 1.35 & 1.21 & 1.20 & 0.08 & 96 & 8.34 & 8.0 & 3.73 & 13.09 & 61.1 & 90.4 \\
\hline & & 6 & 65 & 7.65 & 7.0 & 3.31 & 8.59 & 8.60 & 1.19 & 1.13 & 1.10 & 0.10 & & & & & & & \\
\hline & Wild & 5 & 10 & 6.50 & 6.0 & 2.88 & 8.05 & 7.90 & 1.03 & 1.17 & 1.20 & 0.14 & 37 & 5.62 & 5.0 & 2.64 & 4.66 & 45.3 & 95.9 \\
\hline & & 6 & 27 & 5.30 & 5.0 & 2.52 & 7.66 & 7.50 & 1.06 & 1.10 & 1.10 & 0.16 & & & & & & & \\
\hline
\end{tabular}


Table 5 Parameter estimates of the selected GLMM best explaining variation in survival in the restricted treatments, experiment II

\begin{tabular}{lllll}
\hline Variable & Estimate & $\mathbf{\pm} \mathbf{S E}$ & $\boldsymbol{Z}$ & $\mathbf{P}$ \\
\hline Intercept (Farm, Restricted hatchery) & -10.51 & 2.63 & -3.99 & 0.0001 \\
Hybrid & -0.31 & 0.18 & -1.68 & 0.09 \\
Wild $^{1}$ & -1.11 & 0.21 & -5.37 & $<0.0001$ \\
Restricted semi-natural & -3.79 & 0.39 & -9.72 & $<0.0001$ \\
Egg size $^{2}$ & 20.31 & 4.39 & 4.62 & $<0.0001$ \\
\hline
\end{tabular}

Wald Z-statistics of the selected GLMM fitted using Laplace approximation, with tank nested within treatment as a random intercept and $2 \times 2$ (co) variance matrix allowing for heterogeneity of variance between families across treatments, i.e., random intercept and slope. SE; standard error of estimates. Differences in probability of survival between salmon of farmed, hybrid or wild origin were investigated by re-running the final model while excluding one of the genetic origins at a time, while multiple comparisons were corrected for by the Bonferroni correction, giving an adjusted significance level of 0.017 .

${ }^{1}$ Wild relative to hybrid salmon: estimated value $=-0.81 \pm 0.22, Z=-3.68$, $P=0.0002 .^{2}$ The effect of egg size upon survival was no longer significant in the farmed and hybrid salmon after the Bonferroni correction: estimated value $=15.58 \pm 6.66, Z=2.34, P=0.019$.

displayed significantly flatter slopes than the hybrid and farmed salmon both between the hatchery control and the restricted hatchery treatments and between the hatchery control and the restricted semi-natural treatments (Figure 8; Additional file 5). The slope between the hatchery control and the restricted hatchery treatments were similar in the hybrid and farmed salmon, while the slope between the hatchery control and the restricted semi-natural treatments were significantly flatter in the hybrid salmon, as compared to the farmed salmon (Figure 8, Additional file 5). Thus, wild salmon, both in the restricted hatchery treatment and the restricted semi-natural treatment displayed a larger relative growth than hybrid and farmed salmon, when compared to growth in the hatchery control treatment (Table 4). Farmed and hybrid salmon displayed similar relative growth in the restricted hatchery treatment, while in the restricted semi-natural treatment hybrid salmon displayed a larger relative growth than the farmed salmon (Table 4). In general, no significant genotypeby-environment interaction was detected between the restricted hatchery treatment and the restricted seminatural treatment (Additional file 3).

\section{Influence of family on body weight at termination}

No overlap in mean family weight at termination between the wild, hybrid and farmed salmon were observed in the hatchery control treatment (Figure 7). In the restricted hatchery treatment, overlap in mean family weight between thirteen wild and hybrid families, eleven hybrid and farm families and two wild and farm families were observed (Figure 7). Overlap in mean family weight between families of all three origins was also detected in the restricted semi-natural treatment (Figure 7).

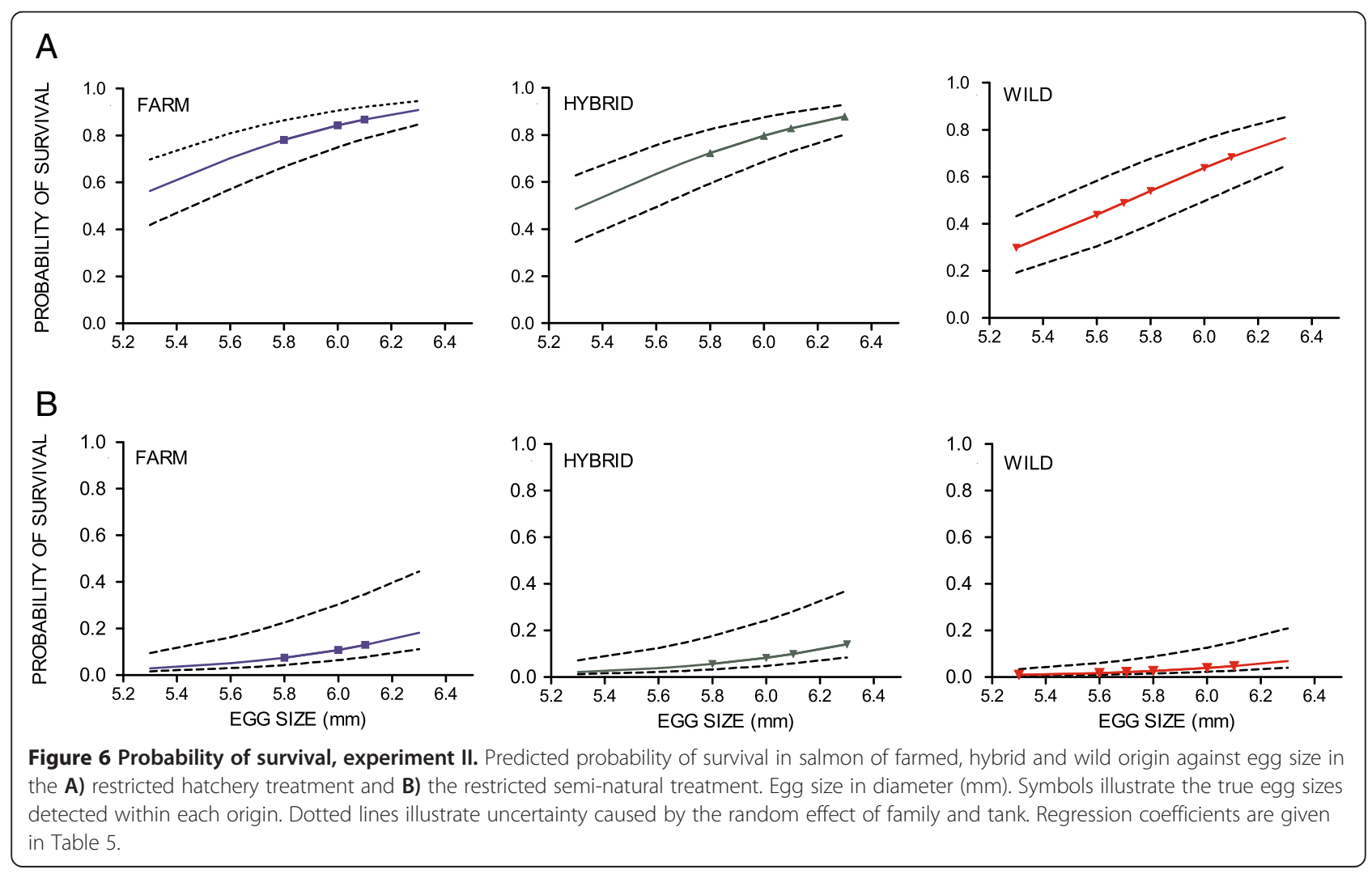




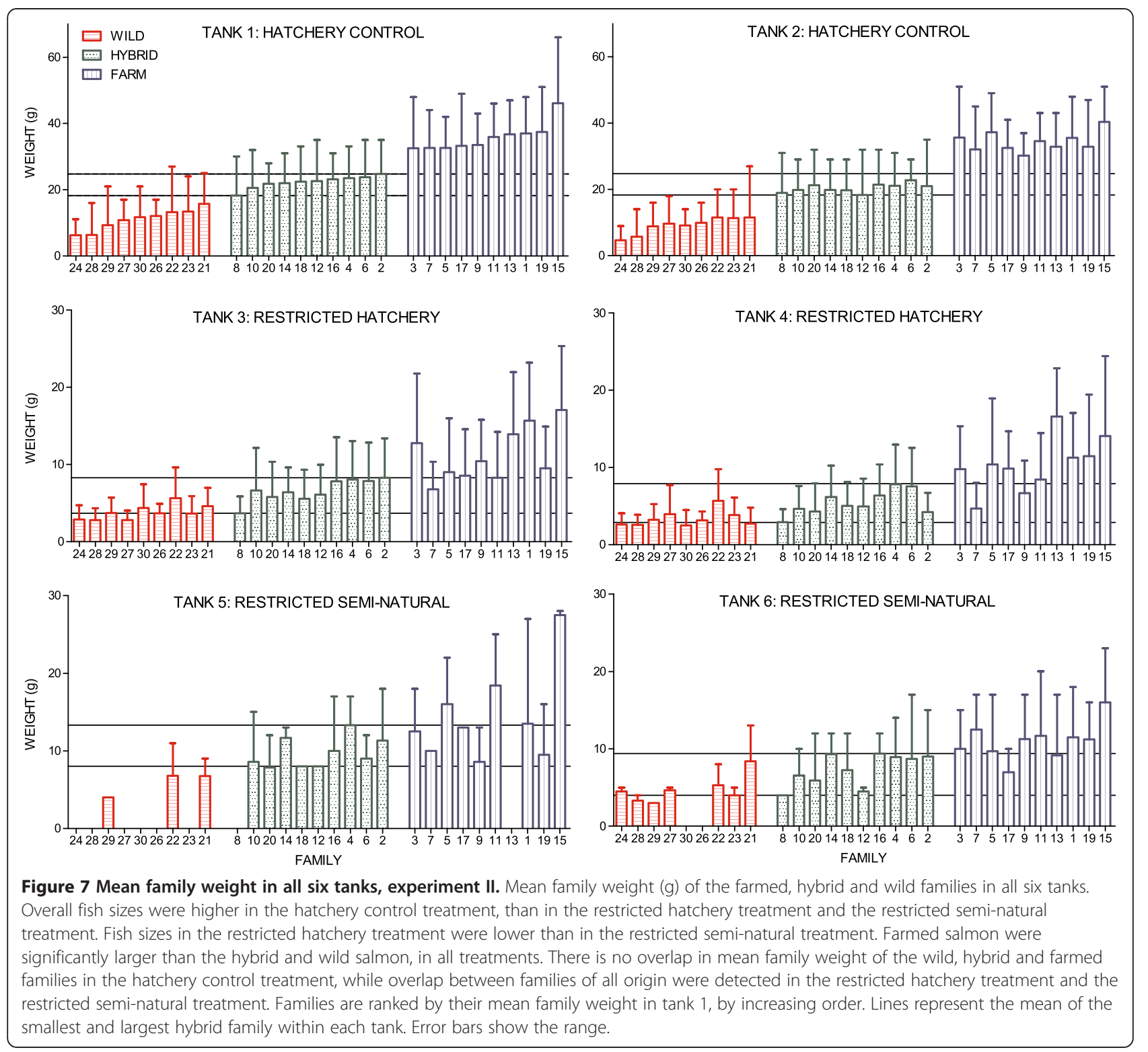

Salmon of all origin displayed a significant correlation between mean family weight in the hatchery control treatment and mean family weight in the restricted hatchery treatment (Wild: $n=36$, Pearson $\mathrm{r}=0.52, \mathrm{P}=0.001$; Hybrid: $n=40$, Pearson $\mathrm{r}=0.52, \mathrm{P}=0.0006$; Farm: $n=40$, Pearson $\mathrm{r}=0.47, \mathrm{P}=0.002$; Figure 9).

\section{Heritability of body weight (experiments I and II)}

For salmon reared under standard hatchery conditions, a larger portion of the observed phenotypic variation was attributed to genetic variation in the wild salmon, than in the farmed and hybrid salmon (see Figures 4 and 9). Hence a higher heritability estimate $h^{2}$ of the trait body weight $\left(\log _{10}\right)$ at termination was detected in the wild salmon, than in the farmed salmon, while the lowest heritability estimates were detected in the hybrid salmon (Table 6). Heritability estimates under standard hatchery conditions increased over time (Table 6). Hence, heritability estimates were higher in experiment I, i.e., mixedstrain treatment, than in experiment II, i.e., hatchery control treatment.

In experiment II, heritability estimates of farmed and hybrid salmon increased in the restricted hatchery treatment, while in the wild salmon heritability estimates decreased (Table 6). In addition, phenotypic variation increased in the farmed and hybrid salmon, while decreased in the wild (detectable by visual examination of Figure 9). Thus, larger plasticity between treatments was detected in the farmed and hybrid salmon, as compared to the wild salmon. Decreased phenotypic variation 


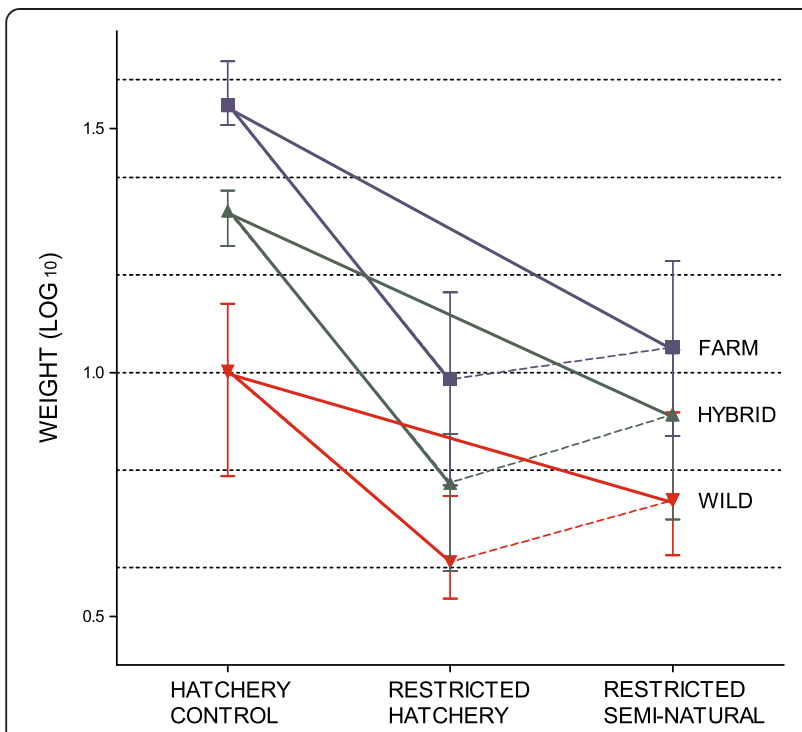

Figure 8 Growth reaction norms across treatments, experiment

II. Mean weight $\left(\log _{10}\right)$ norm of reaction across all treatments for salmon of farmed, hybrid and wild origin. Replicated tanks are pooled. Error bars show the range of the family means within each experimental group. The elevations of the reaction norms were significantly different between the treatments, as well as between the farmed, hybrid and wild salmon. Wild salmon displayed a significantly flatter negative reaction norm slope between the hatchery control and the restricted hatchery treatments than the hybrid and farmed salmon, which displayed similar and steeper slopes. All groups displayed significantly different reaction norm slopes between the hatchery control and the restricted semi-natural treatment, with farmed salmon displaying the steepest slope, followed by the hybrid salmon. Salmon of all origin displayed similar positive reaction norm slopes between the restricted hatchery treatment and the restricted semi-natural treatment.

could be expected in the wild salmon if the high mortality were removing the smallest individuals, thus causing an increase in mean body weight of families.

Broad and overlapping credibility intervals, i.e., 95\% highest posterior density intervals, were detected in both experiments between all origins. Thus, the trend among the origins, more than the isolated $h^{2}$ values itself, indicates the difference in genetic variation of the trait body weight at termination among the origins and treatments.

\section{Discussion}

Introgression of farmed escaped salmon represents a major challenge to the genetic integrity of wild populations. It is therefore important to elucidate and quantify the genetic differences between wild and domesticated salmon in order to understand the potential evolutionary consequences of farmed/wild hybridization and introgression in the wild. This study reports the effect of social interaction and inter-strain competition upon growth under standard hatchery conditions in salmon originating from the farmed Mowi strain, the wild Figgjo strain and their $F_{1}$ hybrids. In addition, the norm of reaction for survival and growth along an environmental gradient with differing competitive intensities was investigated. The main results can be summarised as; (i) under standard hatchery conditions the relative difference in growth between farmed and wild salmon was similar when reared separately and together; (ii) growth of surviving farmed, hybrid and wild salmon became more similar as mortality increased along the environmental gradient approaching natural conditions; (iii) under standard hatchery conditions, mean family weight did not overlap between farmed, hybrid and wild families, while overlap between families of all origins were displayed in the restricted treatments.

\section{Social interaction and inter-strain competition}

Mixing salmon of different genetic backgrounds is frequently done in common-garden experiments $[16,28,45,46]$ in order to avoid origin-specific environmental differences, i.e., tank effects. Results of such studies have revealed difference in growth between wild and farmed salmon at ratios as high as 2.9:1 [28] and concern has been raised if

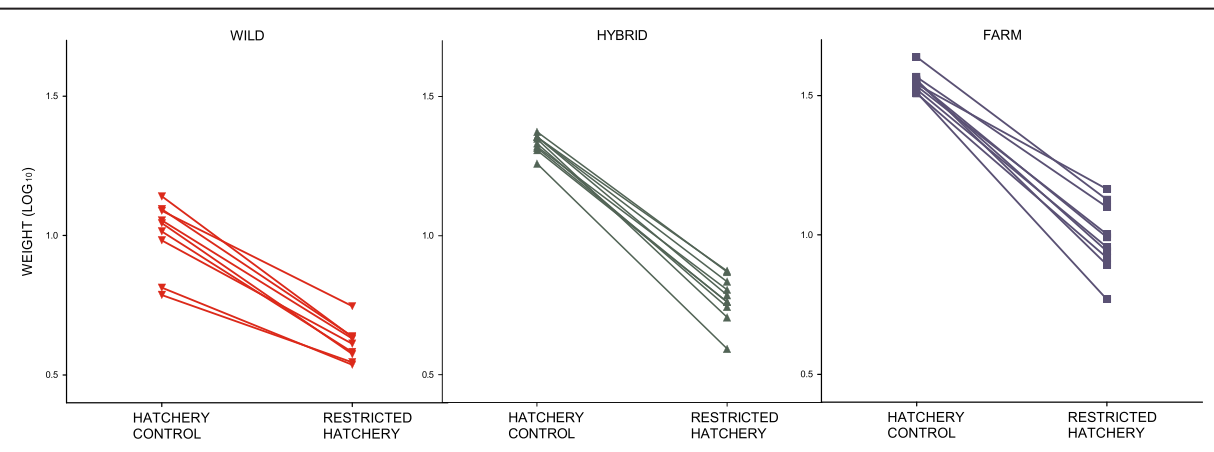

Figure 9 Family growth reaction norms in the hatchery, experiment II. Family weight $\left(\log _{10}\right)$ norm of reaction between the hatchery control treatment and the restricted hatchery treatment for salmon of farmed, hybrid and wild origin. Replicated tanks are pooled. A significant correlation between mean family weight in the hatchery control treatment and mean family weight in the restricted hatchery treatment were detected in salmon of all origins. 
Table 6 Heritability of the trait body weight $\left(\log _{10}\right)$ in salmon of all origins, experiment I and II

\begin{tabular}{|c|c|c|c|c|c|c|}
\hline \multirow[t]{2}{*}{ Experiment } & \multirow[t]{2}{*}{ Model } & \multirow{2}{*}{$\begin{array}{l}\text { Social or physical } \\
\text { treatment }\end{array}$} & \multirow[t]{2}{*}{ Origin } & \multirow[t]{2}{*}{$h 2$} & \multicolumn{2}{|c|}{ HPD interval } \\
\hline & & & & & Lower & Upper \\
\hline \multirow[t]{3}{*}{ । } & 4.1 & Mixed-strain & Farm & 0.33 & 0.16 & 0.82 \\
\hline & 4.2 & & Hybrid & 0.18 & 0.07 & 0.65 \\
\hline & 4.3 & & Wild & 0.70 & 0.36 & 0.92 \\
\hline \multirow[t]{6}{*}{$\|$} & 4.4 & Hatchery control & Farm & 0.16 & 0.00 & 0.57 \\
\hline & 4.5 & & Hybrid & 0.09 & 0.00 & 0.27 \\
\hline & 4.6 & & Wild & 0.51 & 0.10 & 0.85 \\
\hline & 4.7 & Restricted hatchery & Farm & 0.26 & 0.02 & 0.69 \\
\hline & 4.8 & & Hybrid & 0.12 & 0.00 & 0.44 \\
\hline & 4.9 & & Wild & 0.15 & 0.00 & 0.43 \\
\hline
\end{tabular}

Heritability $h^{2}$ of the trait body weight $\left(\log _{10}\right)$ calculated using the animal model, implemented by MCMCglmm. The upper and lower $95 \%$ highest posterior density (HPD) intervals represent the credibility intervals of the estimated $h^{2}$. Models were fitted separately for each experimental group, in all treatments. In addition to the breeding value, Animal, the random effect of tank was included in all models as this improved the fit of the MCMCglmm.

these differences are entirely genetically based or influenced by social interaction. This is because origin-specific differences in competitive ability [19] and aggressiveness $[16,20,82]$ cannot be controlled for in common-garden experiments, nor the influence of social dominance and hierarchy $[20,83]$. In this study, fish in the single-strain treatment were subjected to more movement/handling than the fish in the mixed-strain treatment. Hence temporarily increased stress levels could have affected appetite [84], and as a consequence suppressed growth in salmon of all origins [85]. Although growth across all groups were lower when reared separately, importantly, the relative difference in weight between farmed and wild salmon in this study were similar when reared separately and together. Farmed salmon outgrew wild salmon by a ratio of 5.15:1 and 4.91:1 in the single-strain treatment and mixed-strain treatment, while for hybrid salmon, the adjoining numbers were $1.58: 1$, and $1.87: 1$, respectively. These results indicate that the effects of social interaction and inter-strain competition upon growth in studies where salmon of differing genetic backgrounds are reared communally from the eyed-egg stage onwards are not detectably influencing their relative growth rates. Or put simply, the presence of fastergrowing farm fish did not impair growth rate of the slower-growing wild fish in this study. Therefore, common-garden experiments appear robust for comparative studies on the farmed/wild interface. It is acknowledged however, that the results of this study could be further validated by conducting growth comparisons of other combinations of strains in order to see if this is generically true.

To our knowledge, this is the first study comparing growth of Atlantic salmon reared in single-strain tanks and mixed-strain tanks from the eye-egg stage, although growth performance of salmon reared in single-family and mixed-family tanks has been compared [86]. In the study by Herbinger and colleagues [86] no relationship between mean family weight in the two rearing environments were detected. In our study, a correlation between mean family weight in the mixed-strain treatment and the single-strain treatment were detected in salmon of all origins. Herbinger and colleagues suggested that environmental differences among replicated tanks had a stronger impact on family growth performance than genetic differences among the families in their study, thus highlighting the benefit of common-garden studies where individuals of all origins are reared together [86]. In contrast to our study, larger weight differences between selected and unselected strains of sea bass Dicentrarchus labrax were detected when reared communally, than when reared separately [87]. Although inter-strain competition was likely to contribute to this result, rearing densities in the singlestrain tanks were suggested as a stronger regulating factor [87]. This because biomass densities were higher in the selected than the unselected strains when reared separately, potentially resulting in reduced growth and thus smaller differences [87]. Larger growth difference when reared together than separately, have also been documented in progenies of common carp Cyprinus carpio [88].

\section{Survival and growth along an environmental gradient}

Surviving wild salmon displayed a flatter growth reaction norm slope between the hatchery control treatment and the restricted hatchery treatment, as compared to the hybrid and farmed salmon. Thus, the relative difference in weight between wild and farmed salmon decreased from a ratio of 3.43:1 to 2.86:1, while the adjoining numbers for hybrid and farmed salmon were insignificantly different between the two treatments at 1.64:1 and $1.79: 1$, respectively. A larger difference in weight between wild and farmed salmon in the hatchery control treatment could be caused by farmed salmon utilizing feed better than wild salmon [15,89], and thus the ad 
libitum feeding ration benefited the farmed salmon to a larger extent than the wild salmon. However, in the restricted hatchery treatment, mortality was higher in the wild salmon than in the hybrid and farmed salmon, i.e., 48.4, 21.2 and $18.2 \%$ respectively. Thus, the flatter slope detected in the wild salmon could also have been caused by the high mortality, if mortality was size-selective towards the slow growing individuals under these conditions. We would then predict size-selective mortality to select against salmon of wild, followed by hybrid origin, while favouring farmed salmon, as mortality increased along our environmental gradient. Consistent with this suggestion, both wild and hybrid salmon displayed significantly flatter growth reaction norm slopes between the hatchery control treatment and the restricted seminatural treatment, where overall mortality was much higher. Wild salmon displayed a mortality rate of $95.9 \%$ in the restricted semi-natural treatment, which is close to mortality rates documented in the wild $[14,41]$. Although mortality rates were still insignificantly different between hybrid and farmed salmon, i.e., 90.4 and $87.7 \%$, the relative difference in weight between salmon of all origin decreased in the restricted semi-natural treatment where farmed salmon outgrew wild and hybrid salmon by $2.11: 1$ and 1.42:1, respectively. Thus, growth of surviving farmed, hybrid and wild salmon became more similar as mortality increased along the environmental gradient approaching natural conditions.

The positive relationship observed between egg size and survival were expected, based upon previous studies of Atlantic salmon [41,90] and other salmonids [91,92]. As larger females tend to produce larger eggs [93,94], maternal effects due to differences in size between the wild and farmed parents used in this study are likely to have influenced the low survival rate in the wild salmon where the smallest egg sizes were detected. Egg size has also been documented to be positively related to body size at emergence [91,95], and in the wild even up to $>100$ days post emergence [90]. As the advantage of emerging from large eggs, upon growth and survival, seems to be stronger under direct competition and suboptimal growth conditions $[94,96,97]$, this could indicate that the strong mortality pressure in the early stages of this experiment, was size-selective towards the smallest individuals, and not origin-specific per se.

\section{Plasticity and genetic variation}

Heritability estimates $h^{2}$ of the trait body weight $\left(\log _{10}\right)$ at termination were higher in the wild, than the hybrid and farmed salmon reared under standard hatchery conditions. Thus a larger portion of the observed phenotypic variation was explained by genetic variation in the wild versus the farmed salmon. Reduced genetic variation for growth in farmed salmon is consistent with the theoretical predictions of domestication [98], and were expected based upon a previous study comparing heritability of this trait in farmed and wild salmon originating from the River Etne, Norway [28].

Unfavourable environmental conditions can increase the estimation of quantitative genetic variation, due to variation being masked under more optimal conditions $[99,100]$. Consistent with this theory, heritability of the trait body weight of farmed and hybrid salmon increased in the restricted hatchery treatment, as compared to in the hatchery control treatment. However, for wild salmon the heritability estimates decreased. If the high mortality observed in the wild salmon in the restricted hatchery treatment was random, this should have no impact on plasticity or the heritability estimate of the trait body weight. However, if the observed mortality were size-selective as suggested above, e.g., the smallest wild salmon had a lower probability of surviving than the largest wild salmon, plasticity in family growth could appear smaller, resulting in smaller heritability estimates and less genetic variation $[101,102]$. Thus, the observed decrease in $h^{2}$ for the wild salmon which showed the highest mortality could indicate that mortality was sizespecific in this study.

\section{Implications}

A characteristic feature of domesticated Atlantic salmon is the fact that they outgrow wild salmon extensively under standard hatchery conditions [13,15,16,20,28,37-40]. In this study, farmed salmon outgrew wild salmon at a ratio of 3.43:1 in autumn of their first year and at a ratio of 4.91-5.15:1 in spring the following year (age 1), while the $\mathrm{F}_{1}$ hybrid was outgrown by $1.64: 1$ and $1.58-1.87: 1$ at the corresponding life stages. In comparison, differences in growth between farmed and wild salmon up to the smolt stage appear to be much smaller in the natural environment. Few studies have investigated differences in growth and survival from hatch in salmon of farmed and wild origin in the wild $[14,18,41,42]$, and in some cases the magnitude of the growth differences are not reported $[14,18]$. However, in the most comprehensive of these studies which involved measuring family growth and survival in three year classes of salmon planted in the River Guddalselva, Norway, relative differences observed in growth between wild and farmed salmon were 1:1.07, 1:1.25 and 1:1.06 respectively [41]. Further, in another Norwegian study [42], similar small differences in growth were also observed between farmed and wild salmon in the River Imsa. Thus the question arises: why do farmed salmon outgrow wild salmon several-fold under hatchery conditions but only marginally in the natural environment?

This study demonstrates that social interaction and inter-strain competition in densely stocked mixed origin 
hatchery tanks is not the primary reason as to why farmed salmon in the hatchery outgrow wild salmon in a manner that is not seen in nature. We therefore, tentatively suggest size-selective mortality as a possible underlying factor in reducing differences in growth between wild and farmed salmon in the wild. Size-selective mortality in juvenile teleosts may favour fast growing individuals, as smaller conspecifics have a disadvantage in competition for residence, towards resistance to starvation and parasites, and are more vulnerable for predation [55,103,104], but see [105]. However, reduced anti-predator responses have been documented in farmed and hatchery-reared Atlantic salmon $[16,20,21,106]$ as well as in other domesticated salmonids $[56,107,108]$. Thus, as farmed salmon is more prone to risk, predation-mortality in the wild could select against the bold fast growing farmed individuals. While negative size-selective mortality then selects against small individuals, positive size-selective mortality selects against large individuals, potentially shifting the populations mean weight towards the middle. Although growth of farmed and wild salmon became more similar as mortality increased along the environmental gradient, this experiment only allowed for negative size-selective competition mortality and not positive size-selective predation mortality. Consequently, further scientific attention on elucidating the selection pressure in the wild is encouraged in order to understand if and to what extent size-selective mortality in the wild could explain why farmed salmon outgrow wild salmon more extensively in the hatchery than in the wild.

\section{Conclusions}

Comparative studies of quantitative traits along the wild/ domesticated interface of Atlantic salmon can be used to help understand the potential evolutionary consequences of introgression and hybridization in the wild. This study shows that the large difference in relative growth between wild and farmed salmon detected in the hatchery is similar when reared separately or together. Thus, indicating that social interaction and inter-strain competition are not likely to result in overestimations of genetically based differences in wild and farmed salmon in common-garden experiments. In addition, this study investigated the norm of reaction for survival and growth in Atlantic salmon originating from the farmed Mowi strain, the wild Figgjo strain and their $F_{1}$ hybrids, along an environmental gradient. Restricted feed rations were used to induce nutritional competition in a predator-free-environment, thus allowing for negative size-selective mortality. Based upon the fact that the relative difference in body weight between surviving farmed and wild salmon decreased as mortality increased along the environmental gradient approaching natural conditions, we tentatively suggest a hypothesis that size-selective mortality in the wild could be a possible underlying factor for farmed salmon outgrowing wild salmon less extensively, as compared to in the hatchery. However, further scientific attention on the subject is encouraged.

\section{Availability of supporting information}

The data sets supporting the results of this article are included within the articles additional files (see Additional file 10).

\section{Additional files}

Additional file 1: Family design. Family design and parental origin of Salmo salar L. families used in experiment I and II.

Additional file 2: Water temperature November 23, 2010 - March 20, 2012. Water temperature from family production throughout the study; i) Families are produced and fertilized eggs are incubated in the hatchery; ii) eye-eggs are sorted into experimental groups; iii) eyed-eggs are planted in the semi-natural environment, experiment II (dotted line illustrates the temperature in the semi-natural environment when deviating from the temperature in the hatchery environment); iv) experimental groups are transferred from the hatchery to heated start-feeding tanks, experiment I and II; v) unheated water is supplied from this point and throughout the studies; vi) experiment II is terminated; vii ) experiment I is terminated.

Additional file 3: Model selection LME models. Model selection on the full LME models describing the effect of treatment, origin and egg size, and all interaction effects, upon body weight $\left(\log _{10}\right)$ at termination, experiment I and II.

Additional file 4: Parameter estimates of the selected LME models, including re-runs. $t$-statistics of the best fitted LME models, using REML estimation, describing the effect of treatment and origin upon body weight $\left(\log _{10}\right)$ at termination, experiment I and II.

Additional file 5: F- statistics of the LME models, including re-runs. F-statistics of the best fitted LME models, using ML estimation, describing the effect of treatment and origin upon body weight at termination $\left(\log _{10}\right)$, experiment I and II.

Additional file 6: Model selection GLMM. Model selection on the full GLMM describing the effect of treatment, origin and egg size, and all interaction effects, upon survival in the restricted hatchery treatment and the restricted semi-natural treatment, experiment $I$.

Additional file 7: Parameter estimates of the selected GLMM, including re-runs. Wald Z-statistics of the best fit GLMM, fitted using Laplace approximation, describing the effect of treatment, origin and egg size, upon survival in the restricted hatchery treatment and the restricted semi-natural treatment, experiment II.

Additional file 8: Model selection MCMCglmms. DIC comparisons of the random effect structure of the animal model, implemented by MCMCglmm, experiment I and II.

Additional file 9: Mean family weight in all mixed-strain replicates, experiment I. Mean family weight $(\mathrm{g})$ of the farmed, hybrid and wild families in all four replicates. There is no overlap in mean family weight of the wild, hybrid and farmed families in any of the four tanks. Families are ranked by their mean family weight in the mixed-strain treatment when replicated tanks are pooled, by increasing order. Lines represent the mean of the smallest and largest hybrid family. Error bars show the range.

Additional file 10: Data set. Full data set supporting the results of this study, experiment I and II.

\section{Competing interests}

The authors declare that they have no competing interest. 


\section{Authors' contributions}

MFS and KAG conceived, designed and performed the experiments. MFS, ZZ, FN and KAG analysed the data. MFS, ZZ, FN and KAG wrote the paper. All authors read and approved the final manuscript.

\section{Acknowledgements}

This study was finances by The Research Council of Norway under the project Interact. We greatly acknowledge T. Aga, L. Dyrhovden, I. H. Matre and $\mathrm{K}$. Storsæter at the Matre research station for making it possible to conduct these experiments and F. Besnier for helpful advice towards the statistical analyses. We also acknowledge the constructive criticism of the two anonymous referees.

\section{Author details}

'Section of Population Genetics and Ecology, Institute of Marine Research, P.O. Box 1870, Nordnes, NO-5817 Bergen, Norway. ²Department of Biology, University of Bergen, P.O. Box 7800 N-5020 Bergen, Norway. ${ }^{3}$ Jiangsu Institute of Marine Fisheries, NanTong City, PR China.

Received: 26 April 2013 Accepted: 11 October 2013

Published: 28 October 2013

\section{References}

1. Allendorf FW, Leary RF, Spruell P, Wenburg JK: The problems with hybrids: setting conservation guidelines. Trends Ecol Evol 2001, 16(11):613-622.

2. Randi E: Detecting hybridization between wild species and their domesticated relatives. Mol Ecol 2008, 17(1):285-293.

3. Fiske P, Lund RA, Hansen LP: Relationships between the frequency of farmed Atlantic salmon, Salmo salar L., in wild salmon populations and fish farming activity in Norway, 1989-2004. ICES J Mar Sci 2006, 63(7):1182-1189.

4. Glover KA, Quintela M, Wennevik V, Besnier F, Sørvik AGE, Skaala Ø: Three decades of farmed escapees in the wild: A spatio-temporal analysis of Atlantic salmon population genetic structure throughout Norway. PLoS One 2012, 7(8):e43129.

5. Glover KA, Pertoldi C, Besnier F, Wennevik V, Kent M, Skaala $\varnothing$ : Atlantic salmon populations invaded by farmed escapees: quantifying genetic introgression with a Bayesian approach and SNPs. BMC Genet 2013, 14:74.

6. Crozier WW: Evidence of genetic interaction between escaped farmed salmon and wild Atlantic salmon (Salmo salar L.) in a Northern Irish river. Aquaculture 1993, 113(1-2):19-29.

7. Clifford SL, McGinnity P, Ferguson A: Genetic changes in an Atlantic salmon population resulting from escaped juvenile farm salmon. $J$ Fish Biol 1998, 52(1):118-127.

8. Crozier WW: Escaped farmed salmon, Salmo salar L., in the Glenarm River, Northern Ireland: genetic status of the wild population 7 years on. Fish Manag Ecol 2000, 7(5):437-446.

9. Clifford SL, McGinnity P, Ferguson A: Genetic changes in Atlantic salmon (Salmo salar) populations of Northwest Irish rivers resulting from escapes of adult farm salmon. Can J Fish Aquat Sci 1998, 55(2):358-363.

10. Bourret V, O'Reilly PT, Carr JW, Berg PR, Bernatchez L: Temporal change in genetic integrity suggests loss of local adaptation in a wild Atlantic salmon (Salmo salar) population following introgression by farmed escapees. Heredity 2011, 106(3):500-510.

11. Skaala $\varnothing$, Wennevik $V$, Glover KA: Evidence of temporal genetic change in wild Atlantic salmon, Salmo salar L., populations affected by farm escapees. ICES J Mar Sci 2006, 63(7):1224-1233.

12. Besnier F, Glover KA, Skaala Ø: Investigating genetic change in wild populations: modelling gene flow from farm escapees.

Aquaculture Environment Interactions 2011, 2(1):75-86.

13. Glover KA, Otterå H, Olsen RE, Slinde E, Taranger GL, Skaala Ø: A comparison of farmed, wild and hybrid Atlantic salmon (Salmo salar L.) reared under farming conditions. Aquaculture 2009, 286(3-4):203-210.

14. McGinnity P, Stone C, Taggart JB, Cooke D, Cotter D, Hynes R, McCamley C, Cross TF, Ferguson A: Genetic impact of escaped farmed Atlantic salmon (Salmo salar L.) on native populations: use of DNA profiling to assess freshwater performance of wild, farmed, and hybrid progeny in a natural river environment. ICES J Mar Sci 1997, 54(6):998-1008.

15. Thodesen J, Grisdale-Helland B, Helland SJ, Gjerde B: Feed intake, growth and feed utilization of offspring from wild and selected Atlantic salmon (Salmo salar). Aquaculture 1999, 180(3-4):237-246.
16. Fleming IA, Einum S: Experimental tests of genetic divergence of farmed from wild Atlantic salmon due to domestication. ICES J Mar Sci 1997, 54(6):1051-1063.

17. Gross MR: One species with two biologies: Atlantic salmon (Salmo salar) in the wild and in aquaculture. Can J Fish Aquat Sci 1998, 55:131-144.

18. McGinnity P, Prodohl P, Ferguson K, Hynes R, O'Maoileidigh N, Baker N, Cotter D, O'Hea B, Cooke D, Rogan G, et al: Fitness reduction and potential extinction of wild populations of Atlantic salmon, Salmo salar, as a result of interactions with escaped farm salmon. $P R$ Soc Lond $B$ 2003, 270(1532):2443-2450.

19. Houde ALS, Fraser DJ, Hutchings JA: Fitness-related consequences of competitive interactions between farmed and wild Atlantic salmon at different proportional representations of wild-farmed hybrids. ICES J Mar Sci 2010, 67(4):657-667.

20. Einum S, Fleming IA: Genetic divergence and interactions in the wild among native, farmed and hybrid Atlantic salmon. J Fish Biol 1997, 50(3):634-651.

21. Houde ALS, Fraser DJ, Hutchings JA: Reduced anti-predator responses in multi-generational hybrids of farmed and wild Atlantic salmon (Salmo salar L.). Conservat Genet 2010, 11(3):785-794.

22. Skaala $\varnothing$, Taggart JB, Gunnes K: Genetic differences between five major domesticated strains of Atlantic salmon and wild salmon. J Fish Biol 2005, 67:118-128.

23. Skaala $\varnothing$, Høyheim B, Glover KA, Dahle G: Microsatellite analysis in domesticated and wild Atlantic salmon (Salmo salar L.): allelic diversity and identification of individuals. Aquaculture 2004, 240(1-4):131-143.

24. Karlsson S, Moen T, Lien S, Glover KA, Hindar K: Generic genetic differences between farmed and wild Atlantic salmon identified from a 7K SNP-chip. Mol Ecol Resour 2011, 11:247-253.

25. Roberge C, Normandeau E, Einum S, Guderley H, Bernatchez L: Genetic consequences of interbreeding between farmed and wild Atlantic salmon: insights from the transcriptome. Mol Ecol 2008, 17(1):314-324.

26. Roberge C, Einum S, Guderley H, Bernatchez L: Rapid parallel evolutionary changes of gene transcription profiles in farmed Atlantic salmon. Mol Ecol 2006, 15(1):9-20.

27. Solberg MF, Kvamme BO, Nilsen F, Glover KA: Effects of environmental stress on mRNA expression levels of seven genes related to oxidative stress and growth in Atlantic salmon Salmo salar L. of farmed, hybrid and wild origin. BMC Res Notes 2012, 5:672.

28. Solberg MF, Skaala $\varnothing$, Nilsen F, Glover KA: Does domestication cause changes in growth reaction norms? A study of farmed, wild and hybrid Atlantic salmon families exposed to environmental stress. PLoS One 2013, 8(1):e54469.

29. Hindar K, Ryman N, Utter F: Genetic-effects of aquaculture on natural fish populations. Aquaculture 1991, 98(1-3):259-261.

30. Naylor R, Hindar K, Fleming IA, Goldburg R, Williams S, Volpe J, Whoriskey F, Eagle J, Kelso D, Mangel M: Fugitive salmon: Assessing the risks of escaped fish from net-pen aquaculture. Bioscience 2005, 55(5):427-437.

31. Hindar K, Ryman N, Utter F: Genetic-effects of cultured fish on natural fish populations. Can J Fish Aquat Sci 1991, 48(5):945-957.

32. Ferguson A, Fleming IA, Hindar K, Skaala Ø, McGinnity P, Cross TF, Prodöhl P: Farm escapees. In The Atlantic salmon Genetics, Conservation and Management. Edited by Verspoor E, Stradmeyer L, Nielsen JL. Oxford, UK: Backwell; 2007:357-398.

33. Bentsen HB: Genetic effects of selection on polygenic traits with examples from Atlantic salmon, Salmo salar L. Aquaculture and Fisheries Management 1994, 25(1):89-102.

34. Gjedrem T: Genetic improvement of cold-water fish species. Aquacult Res 2000, 31(1):25-33.

35. Thodesen J, Gjedrem T: Breeding programs on Atlantic salmon in Norway: lessons learned. In Development of aquatic animal genetic improvement and dissemination programs: current status and action plans. Edited by Ponzoni RW, Acosta BO, Ponniah AG. Penang, Malaysia: The WorldFish Center; 2006:22-26.

36. Gjedrem T, Gjøen HM, Gjerde B: Genetic-origin of Norwegian farmed Atlantic salmon. Aquaculture 1991, 98(1-3):41-50.

37. Gjerde B: Growth and reproduction in fish and shellfish. Aquaculture 1986, 57(1-4):37-55

38. Gjedrem T: Selection for growth rate and domestication in Atlantic salmon. J Anim Breed Genet 1979, 96(1):56-59.

39. Fleming IA, Agustsson T, Finstad B, Johnsson JI, Björnsson BT: Effects of domestication on growth physiology and endocrinology of Atlantic salmon (Salmo salar). Can J Fish Aquat Sci 2002, 59(8):1323-1330. 
40. Glover KA, Bergh $\varnothing$, Rudra H, Skaala Ø: Juvenile growth and susceptibility to Aeromonas salmonicida subsp. salmonicida in Atlantic salmon (Salmo salar L.) of farmed, hybrid and wild parentage. Aquaculture 2006, 254(1-4):72-81.

41. Skaala $\varnothing$, Glover KA, Barlaup BT, Svåsand T, Besnier F, Hansen MM, Borgstrøm R: Performance of farmed, hybrid and wild Atlantic salmon (Salmo salar) families in a natural river environment. Can J Fish Aquat Sci 2012, 69:1-13.

42. Fleming IA, Hindar K, Mjølnerød IB, Jonsson B, Balstad T, Lamberg A: Lifetime success and interactions of farm salmon invading a native population. P R Soc Lond B 2000, 267(1452):1517-1523.

43. Huntingford FA: Implications of domestication and rearing conditions for the behaviour of cultivated fishes. J Fish Biol 2004, 65:122-142.

44. Ruzzante DE: Domestication effects on aggressive and schooling behavior in fish. Aquaculture 1994, 120(1-2):1-24.

45. Fraser DJ, Cook AM, Eddington JD, Bentzen P, Hutchings JA: Mixed evidence for reduced local adaptation in wild salmon resulting from interbreeding with escaped farmed salmon: complexities in hybrid fitness. Evol App/ 2008, 1(3):501-512.

46. Glover KA, Hamre LA, Skaala $\varnothing$, Nilsen F: A comparison of sea louse (Lepeophtheirus salmonis) infection levels in farmed and wild Atlantic salmon (Salmo salar L.) stocks. Aquaculture 2004, 232(1-4):41-52.

47. Roff DA: The evolution of life-history parameters in teleosts. Can J Fish Aquat Sci 1984, 41(6):989-1000.

48. Anon: Regionalt tilsynsprosjekt 2011. In Prosjekt overlevelse fisk. Report from the Norwegian Food Safety Authority. ; 2011 (in Norwegian).

49. Brännäs E: First access to territorial space and exposure to strong predation pressure - a conflict in early emerging Atlantic salmon (Salmo salar L.) fry. Evol Ecol 1995, 9(4):411-420.

50. Henderson JN, Letcher BH: Predation on stocked Atlantic salmon (Salmo salar) fry. Can J Fish Aquat Sci 2003, 60(1):32-42.

51. Elliott JM: Spatial-distribution and behavioral movements of migratory trout Salmo trutta in a lake district stream. J Anim Ecol 1986, 55(3):907-922

52. Hutchings JA: Fitness consequences of variation in egg size and food abundance in brook trout Salvelinus fontinalis. Evolution 1991, 45(5):1162-1168.

53. Einum S, Fleming IA: Selection against late emergence and small offspring in Atlantic salmon (Salmo salar). Evolution 2000, 54(2):628-639.

54. Taylor EB, McPhail JD: Burst swimming and size-related predation of newly emerged coho salmon Oncorhynchus kisutch. Trans Am Fish Soc 1985, 114(4):546-551.

55. Boyce NPJ: Biology of Eubothrium salvelini (Cestoda: Pseudophyllidea), a parasite of juvenile sockeye salmon (Oncorhynchus nerka) of Babine-lake, British Columbia. J Fish Res Board Can 1974, 31(11):1735-1742.

56. Berejikian BA: The effects of hatchery and wild ancestry and experience on the relative ability of steelhead trout fry (Oncorhynchus mykiss) to avoid a benthic predator. Can J Fish Aquat Sci 1995, 52(11):2476-2482.

57. Anon: Status for norske laksebestander i 2012. Report from the scientific council of salmon management 2012, 4:89-95. in Norwegian.

58. Lund RA, Hansen LP, Jarvi T: Identifisering av oppdrettslaks og vill-laks ved ytre morfologi, finnestørrelse og skjellkarakterer. Research report from the Norwegian Institute for Nature Research 1989, 1:1-54 (in Norwegian).

59. Barlaup BT, Gabrielsen SE, Skoglund H, Wiers T: Addition of spawning gravel - A means to restore spawning habitat of Atlantic salmon (Salmo salar L.), and anadromous and resident brown trout (Salmo trutta $\mathrm{L}$.) in regulated rivers. River Res Appl 2008, 24(5):543-550.

60. Kilkenny C, Browne WJ, Cuthill IC, Emerson M, Altman DG: Improving bioscience research reporting: the ARRIVE guidelines for reporting animal research. PLOS Biol 2010, 8(6):e1000412.

61. Sánchez JA, Clabby C, Ramos D, Blanco G, Flavin F, Vazquez E, Powell R: Protein and microsatellite single locus variability in Salmo salar L. (Atlantic salmon). Heredity 1996, 77:423-432.

62. O'Reilly PT, Hamilton LC, McConnell SK, Wright JM: Rapid analysis of genetic variation in Atlantic salmon (Salmo salar) by PCR multiplexing of dinucleotide and tetranucleotide microsatellites. Can J Fish Aquat Sci 1996, 53(10):2292-2298.

63. Grimholt U, Drablos F, Jørgensen SM, Hoyheim B, Stet RJM: The major histocompatibility class I locus in Atlantic salmon (Salmo salar L.): polymorphism, linkage analysis and protein modelling. Immunogenetics 2002, 54(8):570-581.

64. Stet RJM, de Vries B, Mudde K, Hermsen T, van Heerwaarden J, Shum BP, Grimholt U: Unique haplotypes of co-segregating major histocompatibility class II A and class II B alleles in Atlantic salmon (Salmo salar) give rise to diverse class II genotypes. Immunogenetics 2002, 54(5):320-331.
65. Slettan A, Olsaker I, Lie O: Atlantic salmon, Salmo salar, microsattelites at the SsOSL25, SsOSL85, SsOSL311, SsOSL417 loci. Anim Genet 1995, 26(4):281-282.

66. Taggart JB: FAP: an exclusion-based parental assignment program with enhanced predictive functions. Mol Ecol Notes 2007, 7(3):412-415.

67. Glover KA, Taggart JB, Skaala $\varnothing$, Teale AJ: Comparative performance of juvenile sea trout families in high and low feeding environments. J Fish Biol 2001, 59(1):105-115.

68. Glover KA, Taggart JB, Skaala $\varnothing$, Teale AJ: A study of inadvertent domestication selection during start-feeding of brown trout families. J Fish Biol 2004, 64(5):1168-1178.

69. Glover KA, Hansen MM, Lien S, Als TD, Hoyheim B, Skaala Ø: A comparison of SNP and STR loci for delineating population structure and performing individual genetic assignment. BMC Genet 2010, 11:2.

70. Glover KA: Forensic identification of fish farm escapees: the Norwegian experience. Aquaculture Environment Interactions 2010, 1(1):1-10.

71. Glover KA, Skilbrei OT, Skaala Ø: Genetic assignment identifies farm of origin for Atlantic salmon Salmo salar escapees in a Norwegian fjord. ICES J Mar Sci 2008, 65(6):912-920.

72. R: A Language and Environment for Statistical Computing. http://www.R-project.org/

73. Ime4: Linear mixed-effects models using $S 4$ classes. $R$ package version 0.999999-0. http://Ime4.r-forge.r-project.org/.

74. Keene ON: The log transformation is special. Stat Med 1995, 14(8):811-819.

75. Hairston NG, Holtmeier CL, Lampert W, Weider L, Post DM, Fischer JM, Caceres CE, Fox JA, Gaedke U: Natural selection for grazer resistance to toxic cyanobacteria: Evolution of phenotypic plasticity? Evolution 2001, 55(11):2203-2214

76. Cole TJ: Sympercents: symmetric percentage differences on the $100 \mathrm{log}$ (e) scale simplify the presentation of log transformed data. Stat Med 2000, 19(22):3109-3125.

77. Zuur A, leno EN, Walker NJ: DSaveliev AA, Smith GM: Mixed effects models and extensions in ecology with R New York. USA: Springer; 2009.

78. Bolker BM, Brooks ME, Clark CJ, Geange SW, Poulsen JR, Stevens MHH, White JSS: Generalized linear mixed models: a practical guide for ecology and evolution. Trends Ecol Evol 2009, 24(3):127-135.

79. Hadfield JD: MCMC Methods for multi-response generalized linear mixed models: the MCMCglmm R package. J Stat Software 2010, 33(2):1-22.

80. Wilson AJ, Reale D, Clements MN, Morrissey MM, Postma E, Walling CA, Kruuk LEB, Nussey DH: An ecologist's guide to the animal model. J Anim Ecol 2009, 79(1):13-26.

81. Kruuk LEB: Estimating genetic parameters in natural populations using the 'animal model'. Philosophical Transactions of the Royal Society of London Series B-Biological Sciences 2004, 359(1446):873-890.

82. Metcalfe NB, Valdimarsson SK, Morgan IJ: The relative roles of domestication, rearing environment, prior residence and body size in deciding territorial contests between hatchery and wild juvenile salmon. J Appl Ecol 2003, 40(3):535-544.

83. Koebele BP: Growth and the size hierarchy effect - an experimental assessment of three proposed mechanisms - activity differences, disproportional food acquisition, physiological stress. Environ Biol Fishes 1985, 12(3):181-188.

84. Woodward CC, Strange RJ: Physiological stress responses in wild and hatchery-reared rainbow-trout. Trans Am Fish Soc 1987, 116(4):574-579.

85. Basrur TV, Longland R, Wilkinson RJ: Effects of repeated crowding on the stress response and growth performance in Atlantic salmon (Salmo salar). Fish Physiol Biochem 2010, 36(3):445-450.

86. Herbinger CM, O'Reilly PT, Doyle RW, Wright JM, O'Flynn F: Early growth performance of Atlantic salmon full-sib families reared in single family tanks versus in mixed family tanks. Aquaculture 1999, 173(1-4):105-116.

87. Vandeputte M, Dupont-Nivet M, Haffray P, Chavanne H, Cenadelli S, Parati K, Vidal $\mathrm{MO}$, Vergnet A, Chatain B: Response to domestication and selection for growth in the European sea bass (Dicentrarchus labrax) in separate and mixed tanks. Aquaculture 2009, 286(1-2):20-27.

88. Wohlfarth GW, Moav R: Communal testing, a method of testing the growth of different genetic groups of common carp in earthen ponds. Aquaculture 1985, 48(2):143-157.

89. Thodesen J, Gjerde B, Grisdale-Helland B, Storebakken T: Genetic variation in feed intake, growth and feed utilization in Atlantic salmon (Salmo salar). Aquaculture 2001, 194(3-4):273-281.

90. Einum S, Fleming IA: Highly fecund mothers sacrifice offspring survival to maximize fitness. Nature 2000, 405(6786):565-567. 
91. Beacham TD, Withler FC, Morley RB: Effect of egg size on incubation-time and alevin and fry size in chum salmon (Oncorhynchus keta) and coho salmon (Oncorhynchus kisutch). Can J Zool 1985, 63(4):847-850.

92. Heath DD, Fox CW, Heath JW: Maternal effects on offspring size: variation through early development of chinook salmon. Evolution 1999, 53(5):1605-1611.

93. Beacham TD: Revisiting trends in the evolution of egg size in hatchery-enhanced populations of chinook salmon from British Columbia. Trans Am Fish Soc 2010, 139(2):579-585.

94. Fleming IA: Reproductive strategies of Atlantic salmon: Ecology and evolution. Rev Fish Biol Fish 1996, 6(4):379-416.

95. Gilbey J, McLay A, Houlihan D, Verspoor E: Individual-level analysis of pre- and post first-feed growth and development in Atlantic salmon. J Fish Biol 2005, 67(5):1359-1369.

96. Einum S, Fleming IA: Maternal effects of egg size in brown trout (Salmo trutta): norms of reaction to environmental quality. Proceedings of the Royal Society B-Biological Sciences 1999, 266(1433):2095-2100.

97. Robertsen $G$, Skoglund $H$, Einum S: Offspring size effects vary over fine spatio-temporal scales in Atlantic salmon (Salmo salar). Can J Fish Aquat Sci 2013, 70(1):5-12

98. Gavrilets S, Scheiner SM: The genetics of phenotypic plasticity. 5 . Evolution of reaction norm shape. J Evol Biol 1993, 6(1):31-48.

99. Hoffmann AA, Merilä J: Heritable variation and evolution under favourable and unfavourable conditions. Trends Ecol Evol 1999, 14(3):96-101.

100. Ghalambor CK, McKay JK, Carroll SP, Reznick DN: Adaptive versus non-adaptive phenotypic plasticity and the potential for contemporary adaptation in new environments. Funct Ecol 2007, 21(3):394-407.

101. Smith PJ, Francis R, McVeagh M: Loss of genetic diversity due to fishing pressure. Fish Res 1991, 10(3-4):309-316.

102. Law R: Fishing, selection, and phenotypic evolution. ICES J Mar Sci 2000, 57(3):659-668

103. Feltham MJ: The diet of red-breasted mergansers (Mergus serrator) during the smolt run in ne scotland - the importance of salmon (Salmo salar) smolts and parr. J Zool 1990, 222:285-292.

104. West CJ, Larkin PA: Evidence for size-selective mortality of juvenile sockeye-salmon (Oncorhynchus nerka) in babine lake, british-columbia. Can J Fish Aquat Sci 1987, 44(4):712-721.

105. Sogard SM: Size-selective mortality in the juvenile stage of teleost fishes: A review. Bulletin of Marine Science 1997, 60(3):1129-1157.

106. Jackson CD, Brown GE: Differences in antipredator behaviour between wild and hatchery-reared juvenile Atlantic salmon (Salmo salar) unde seminatural conditions. Can J Fish Aquat Sci 2011, 68(12):2157-2165.

107. Tymchuk WE, Biagi C, Withler R, Devlin RH: Growth and behavioral consequences of introgression of a domesticated aquaculture genotype into a native strain of Coho salmon. Trans Am Fish Soc 2006, 135(2):442-455.

108. Yamamoto T, Reinhardt UG: Dominance and predator avoidance in domesticated and wild masu salmon Oncorhynchus masou. Fish $\mathrm{SCi}$ 2003, 69(1):88-94.

doi:10.1186/1471-2148-13-234

Cite this article as: Solberg et al: Growth reaction norms of domesticated, wild and hybrid Atlantic salmon families in response to differing social and physical environments. BMC Evolutionary Biology 2013 13:234

\section{Submit your next manuscript to BioMed Central and take full advantage of:}

- Convenient online submission

- Thorough peer review

- No space constraints or color figure charges

- Immediate publication on acceptance

- Inclusion in PubMed, CAS, Scopus and Google Scholar

- Research which is freely available for redistribution 